\title{
Pulse Shaping Techniques for Testing Brittle Materials with a Split Hopkinson Pressure Bar
}

\author{
by D. J. Frew, M. J. Forrestal and W. Chen
}

ABSTRACT- We present pulse shaping techniques to obtain compressive stress-strain data for brittle materials with the split Hopkinson pressure bar apparatus. The conventional split Hopkinson pressure bar apparatus is modified by shaping the incident pulse such that the samples are in dynamic stress equilibrium and have nearly constant strain rate over most of the test duration. A thin disk of annealed or hard C11000 copper is placed on the impact surface of the incident bar in order to shape the incident pulse. After impact by the striker bar, the copper disk deforms plastically and spreads the pulse in the incident bar. We present an analytical model and data that show a wide variety of incident strain pulses can be produced by varying the geometry of the copper disks and the length and striking velocity of the striker bar. Model predictions are in good agreement with measurements. In addition, we present data for a machineable glașs ceramic material, Macor, that shows pulse shaping is required to obtain dynamic stress equilibrium and nearly constant strain rate over most of the test duration.

$\overline{D . J . F r e w}$ is Research Engineer, USAERDC Waterways Experiment Station, Vicksburg, MS 39180-6199. M. J. Forrestal (SEM Member) is Distinguished Member of Technical Staff, Sandia National Laboratories, Albuquerque, NM 87185-0303. W. Chen (SEM Member) is Assistant Professor, Department of Aerospace and Mechanical Engineering, The University of Arizona, Tucson, AZ 85721-0119. 


\section{DISCLAIMER}

This report was prepared as an account of work sponsored by an agency of the United States Government. Neither the United States Government nor any agency thereof, nor any of their employees, make any warranty, express or implied, or assumes any legal liability or responsibility for the accuracy, completeness, or usefulness of any information, apparatus, product, or process disclosed, or represents that its use would not infringe privately owned rights. Reference herein to any specific commercial product, process, or service by trade name, trademark, manufacturer, or otherwise does not necessarily constitute or imply its endorsement, recommendation, or favoring by the United States Government or any agency thereof. The views and opinions of authors expressed herein do not necessarily state or reflect those of the United States Government or any agency thereof. 


\section{DISCLAIMER}

Portions of this document may be illegible in electronic image products. Images are produced from the best available original document. 
Introduction

NOV 152000

\section{OSTI}

The split Hopkinson pressure bar (SHPB) technique originally developed by Kolsky ${ }^{1,2}$ has been used by many investigators to obtain dynamic compression properties of solid materials. The evolution of this experimental method and recent advances are discussed by Nicholas ${ }^{3}$, Nemat-Nasser, Isaacs, and Starrett ${ }^{4}$, Ramesh and Narasimhan ${ }^{5}$, Gray $^{6}$, and Gray and Blumenthal. ${ }^{7}$ This technique has mostly been used to study the plastic flow stress of metals that undergo large strains at strain rates between $10^{2}-10^{4} \mathrm{~s}^{-1}$. As discussed by Yadav, Chichili, and Ramesh $^{8}$, data for the compressive flow stress of metals are typically obtained for strains larger than a few percent because the technique is not capable of measuring the elastic and early yield behavior. By contrast, most of the material behavior of interest for relatively brittle materials such as ceramics and rocks occurs at strains less than about 1.0 percent.

For an ideal Kolsky compression bar experiment, the sample should be in dynamic stress equilibrium and deform at a nearly constant strain rate over most of the test duration. To approximate these ideal conditions for brittle ceramic materials, Nemat-Nasser, Isaacs, and Starrett ${ }^{4}$ modified the conventional Kolsky compression bar by placing an oxygen-free-copper (OFHC) disk on the impact surface of the incident bar. When the striker bar impacts the copper disk, the large plastic deformation of the disk spreads the pulse in the incident bar and allows time for the ceramic sample to achieve dynamic stress equilibrium. Thus, shaping the pulse in the incident bar is an essential modification for testing ceramics with the compression Kolsky bar technique. Experiments that attempt to obtain high-rate, stress-strain data for ceramic materials at constant strain rates are reported by Rogers and Nemat-Nasser ${ }^{9}$ and Chen and Ravichandran. ${ }^{10}$ In addition, Nemat-Nasser, Isaacs, and Starrett ${ }^{4}$ present a model that predicts the strain pulse in the incident bar for an OFHC copper pulse shaper, and Ravichandran and Subash ${ }^{11}$ present a 
sample equilibrium model for ceramic materials. More recently, Frew, Forrestal, and Chen ${ }^{12}$ extended this work ${ }^{4,11}$ to obtain high-rate, stress-strain data for limestone samples. Data from experiments with limestone samples showed that the samples were in dynamic stress equilibrium and had nearly constant strain rates over most the test durations for a ramp pulse in the incident bar.

While pulse shaping techniques have been successfully used to achieve the goals of many different experiments, pulse shapers are usually designed by experimental trials that exclude a model to guide the design parameters. For example, Duffy, Campbell, and Hawley ${ }^{13}$ used a pulse shaper to smooth pulses generated by explosive loading for torsional Hopkinson bar experiments, and $\mathrm{Wu}$ and Gorham ${ }^{14}$ used paper on the impact surface of the incident bar to eliminate high frequency oscillations in the incident pulse for Kolsky compression bar experiments. Togami, Baker, and Forrestal ${ }^{15}$ used a thin, plexiglass disk to produce nondispersive compression pulses in an incident bar, and Chen, Zhang, and Forrestal ${ }^{16}$ used a polymer disk to spread the incident compressive pulses for experiments with elastomers. Christensen, Swanson, and Brown ${ }^{17}$ used striker bars with a truncated-cone on the impact end in an attempt to produce ramp pulses. In contrast to other pulse shaping studies, Nemat-Nasser, Isaacs, and Starrett ${ }^{4}$ model the plastic deformation of an OFHC copper pulse shaper, predict the incident strain pulse, and show good agreement with some measured incident strain pulses.

In this study, we extend the analytical model of Nemat-Nasser, Isaacs, and Starrett ${ }^{4}$ and present new data for annealed and hard $\mathrm{C} 11000^{18}$ copper pulse shapers. Experiments conducted with both OFHC and $\mathrm{C} 11000$ copper pulse shapers showed a superior performance by the C11000 materials. In particular, the $\mathrm{C} 11000$ pulse shapers could be driven to larger strains without breakup or fracture and remained more circular after deformation. We found that with 
both annealed and hard C11000 pulse shapers, we could obtain a broad range of strain rates for testing brittle ceramic and rock ${ }^{12}$ materials. The previous model ${ }^{4}$ was extended to accommodate the large strains obtained in the C11000 copper materials. In addition, we present data for the ceramic material Macor ${ }^{19}$ that shows pulse shaping is required to obtain dynamic stress equilibrium and nearly constant strain rate over most of the test duration.

\section{Split Hopkinson Pressure Bar (SHPB) or Kolsky Bar}

As shown in Fig. 1, a conventional split Hopkinson pressure bar (SHPB) consists of a striker bar, an incident bar, a transmission bar, and a sample placed between the incident and transmission bars. A gas gun launches the striker bar at the incident bar and that impact causes an elastic compression wave to travel in the incident bar towards the sample. When the impedance of the sample is less than that of the bars, an elastic tensile wave is reflected into the incident bar and an elastic compression wave is transmitted into the transmission bar. If the elastic stress pulses in the bars are nondispersive and the specimen deforms with homogeneous deformation, the elementary theory for wave propagation in bars can be used to calculate the sample response from measurements taken with strain gages mounted on the incident and transmission bars. Strain gages mounted on the incident bar measure the incident $\varepsilon_{\mathrm{i}}$ and reflected $\varepsilon_{\mathrm{r}}$ strain pulses, and strain gages mounted on the transmission bar measure the transmitted $\varepsilon_{t}$ strain pulse. Nicholas ${ }^{3}$, and $\mathrm{Gray}^{6}$ present equations that describe the sample response in terms of the measured strain signals.

For this study the incident and transmission bars were made from the same material with equal cross-sectional areas. As shown in Fig. 1, the bars have density $\rho$, Young's modulus E, bar wave speed c, and cross-sectional area A. Since we only focus on brittle materials that have 
failure strains less than about 1.0 percent, we need only use engineering stress, strain, and strainrate measures. In addition, we take stress positive in compression, strain positive in contraction, and particle velocity positive to the right in Fig. 1. Figure 1 also shows the sample has crosssectional area $A_{s}$ and length $l_{0}$. We take subscripts 1 and 2 to represent the locations of the ends of the sample.

From Nicholas ${ }^{3}$

$$
\begin{gathered}
\sigma_{1}=\frac{\mathrm{EA}}{\mathrm{A}_{\mathrm{s}}}\left(\varepsilon_{\mathrm{i}}+\varepsilon_{\mathrm{r}}\right) \\
\sigma_{2}=\frac{\mathrm{EA}}{\mathrm{A}_{\mathrm{s}}} \varepsilon_{\mathrm{t}}
\end{gathered}
$$

If $\sigma_{1}=\sigma_{2}$, the stresses on both ends of the sample are equal, the sample is in dynamic stress equilibrium, and the stress, strain rate, and strain are given by

$$
\begin{gathered}
\sigma_{\mathrm{s}}=\frac{\mathrm{EA}}{\mathrm{A}_{\mathrm{s}}} \varepsilon_{\mathrm{t}} \\
\frac{\mathrm{d} \varepsilon_{\mathrm{s}}}{\mathrm{dt}}=\frac{-2 \mathrm{c}}{1_{\mathrm{o}}} \varepsilon_{\mathrm{r}} \\
\varepsilon_{\mathrm{s}}=\frac{-2 \mathrm{c}}{\mathrm{l}_{\mathrm{o}}} \int_{0}^{\mathrm{t}} \varepsilon_{\mathrm{r}}(\tau) \mathrm{d} \tau .
\end{gathered}
$$

As discussed in detail by Ravichandran and Subash ${ }^{11}$, Gray ${ }^{6}$, and Gray and Blumenthal ${ }^{7}$, 
eqs (2), (3), and (4) assume that the sample is in dynamic stress equilibrium. Equilibrium should first be examined by comparing the stresses $\sigma_{1}$ and $\sigma_{2}$ at the ends of the sample given by eqs (1a) and (1b). If $\sigma_{1}$ and $\sigma_{2}$ are in reasonable agreement, only then it is reasonable to use eqs (2), (3), and (4) to calculate sample stress, strain rate, and strain.

\section{Models for Sample Equilibrium and Constant Strain Rate}

In a recent paper ${ }^{12}$, we presented models that predict the evolutionary process for sample equilibrium and constant strain rate for brittle materials that have a linear stress-strain response until failure. These models were limited to a ramp stress pulse in the incident bar and provided valueable experimental design information for limestone samples. In our more recent work with brittle materials, we learned that it was relatively easy to obtain sample equilibrium and more difficult to obtain a nearly constant strain rate over most of the test duration. To assist our experimental design procedures prior to testing, we extend our previous models ${ }^{12}$ to include a general incident stress pulse. The more general models allow us to examine incident pulses that produce nearly constant strain rates in the sample for a broader range of strain rates. The first model assumes that the sample is in dynamic stress equilibrium and predicts strain and strain rate versus time. For the second model, we perform a wave propagation analysis on the interaction of the sample with the incident and transmission bars. This second model predicts the stress-time histories on either side of the sample.

From the derivations in Frew, Forrestal, and $\mathrm{Chen}^{12}$, sample strain is governed by the differential equation 


$$
\frac{\mathrm{d} \varepsilon_{\mathrm{s}}}{\mathrm{dt}}+\frac{2 \mathrm{~A}_{\mathrm{s}} \mathrm{E}_{\mathrm{s}}}{\rho \mathrm{cAl} l_{\mathrm{o}}} \varepsilon_{\mathrm{s}}=\frac{2 \sigma_{\mathrm{i}}(\mathrm{t})}{\rho \mathrm{cl} \mathrm{l}_{\mathrm{o}}}
$$

where the sample has the linear stress-strain relation

$$
\sigma_{\mathrm{s}}=\mathrm{E}_{\mathrm{s}} \varepsilon_{\mathrm{s}}
$$

and $\sigma_{i}(t)$ is the incident pulse at the incident bar/ sample interface. For a polynomial incident stress

$$
\sigma_{\mathrm{i}}(\mathrm{t})=\sigma_{\mathrm{o}}+\mathrm{Mt}+\mathrm{Nt}^{2}
$$

equation (5) has solutions

$$
\begin{gathered}
\frac{\mathrm{d} \varepsilon_{\mathrm{s}}}{\mathrm{dt}}=\frac{2 \sigma_{0} \gamma}{\mathrm{E}_{\mathrm{s}} \mathrm{rt}} \exp \left(\frac{-2 \mathrm{t}}{\mathrm{rt}}\right)+\frac{\gamma \mathrm{M}}{\mathrm{E}_{\mathrm{s}}}\left[1-\exp \left(\frac{-2 \mathrm{t}}{\mathrm{r} \mathrm{t}_{\mathrm{o}}}\right)\right]+ \\
\frac{\mathrm{N} \gamma \mathrm{t}_{\mathrm{o}} \mathrm{r}}{\mathrm{E}_{\mathrm{s}}}\left[-1+\frac{2 \mathrm{t}}{\mathrm{r} \mathrm{t}_{\mathrm{o}}}+\exp \left(\frac{-2 \mathrm{t}}{\mathrm{rt}}\right)\right] \\
\varepsilon_{\mathrm{s}}=\frac{\sigma_{0} \gamma}{\mathrm{E}_{\mathrm{s}}}\left[1-\exp \left(\frac{-2 \mathrm{t}}{\mathrm{rt}}\right)\right]+\frac{\gamma \mathrm{M}}{\mathrm{E}_{\mathrm{s}}}\left[\mathrm{t}-\frac{\mathrm{rt}}{2}\left(1-\exp \left(\frac{-2 \mathrm{t}}{\mathrm{rt}}\right)\right)\right]+ \\
\frac{N \gamma\left(\mathrm{rt} \mathrm{t}_{\mathrm{o}}\right)^{2}}{2 \mathrm{E}_{\mathrm{s}}}\left[1+\left(\frac{-2 \mathrm{t}}{\mathrm{rt}}\right)+2\left(\frac{\mathrm{t}}{\mathrm{rt}}\right)^{2}-\exp \left(\frac{-2 \mathrm{t}}{\mathrm{rt}}\right)\right] . \\
\gamma=\frac{\mathrm{A}}{\mathrm{A}_{\mathrm{s}}}, \quad \mathrm{r}=\frac{\mathrm{A} \rho \mathrm{c}}{\mathrm{A}_{\mathrm{s}} \rho_{\mathrm{s}} \mathrm{c}_{\mathrm{s}}}, \quad \mathrm{t}_{\mathrm{o}}=\frac{l_{\mathrm{o}}}{\mathrm{c}_{\mathrm{s}}}
\end{gathered}
$$


Equations (8a) and (8b) give closed-form solutions for the strain rate and strain in the sample. However, this model assumes that the sample is in equilibrium.

For the second model, we perform a wave propagation analysis on the interaction of the sample with the incident and transmission bars. Following the procedure developed by Frew, Forrestal, and $\mathrm{Chen}^{12}$, the stresses in the sample at interface 1 shown in Fig. 1 are

$$
\begin{array}{cr}
\sigma_{\mathrm{l}}=\frac{2 \gamma}{\mathrm{r}+1} \sigma_{\mathrm{i}}(\mathrm{t}), & 0 \leq \mathrm{t}<2 \mathrm{t}_{\mathrm{o}} \\
\sigma_{1}=\frac{2 \gamma}{\mathrm{r}+1} \sigma_{\mathrm{i}}(\mathrm{t})+\frac{2 \gamma}{\mathrm{r}+1}\left[\left(\frac{\mathrm{r}-1}{\mathrm{r}+1}\right)+\left(\frac{\mathrm{r}-1}{\mathrm{r}+1}\right)^{2}\right] \sigma_{\mathrm{i}}\left(\mathrm{t}-2 \mathrm{t}_{\mathrm{o}}\right), & 2 \mathrm{t} \mathrm{o} \leq \mathrm{t}<4 \mathrm{t}_{\mathrm{o}} \quad(9 \mathrm{~b}) \\
\sigma_{1}=\frac{2 \gamma}{\mathrm{r}+1} \sigma_{\mathrm{i}}(\mathrm{t})+\frac{2 \gamma}{\mathrm{r}+1}\left[\left(\frac{\mathrm{r}-1}{\mathrm{r}+1}\right)+\left(\frac{\mathrm{r}-1}{\mathrm{r}+1}\right)^{2}\right] \sigma_{\mathrm{i}}(\mathrm{t}-2 \mathrm{t} \mathrm{o})+\frac{2 \gamma}{\mathrm{r}+1}\left[\left(\frac{\mathrm{r}-1}{\mathrm{r}+1}\right)^{3}+\left(\frac{\mathrm{r}-1}{\mathrm{r}+1}\right)^{4}\right] \sigma_{\mathrm{i}}\left(\mathrm{t}-4 \mathrm{t}_{\mathrm{o}}\right), \\
4 \mathrm{t}_{\mathrm{o}} \leq \mathrm{t}<6 \mathrm{t}_{\mathrm{o}} \quad(9 \mathrm{c})
\end{array}
$$

and that at interface 2 are

$$
\begin{array}{cr}
\sigma_{2}=0, & 0 \leq \mathrm{t}<\mathrm{t}_{\mathrm{o}} \\
\sigma_{2}=\frac{2 \gamma}{\mathrm{r}+1}\left[1+\left(\frac{\mathrm{r}-1}{\mathrm{r}+1}\right)\right] \sigma_{\mathrm{i}}\left(\mathrm{t}-\mathrm{t}_{\mathrm{o}}\right) & \mathrm{t}_{\mathrm{o}} \leq \mathrm{t}<3 \mathrm{t}_{\mathrm{o}} \\
\sigma_{2}=\frac{2 \gamma}{\mathrm{r}+1}\left[1+\left(\frac{\mathrm{r}-1}{\mathrm{r}+1}\right)\right] \sigma_{\mathrm{i}}\left(\mathrm{t}-\mathrm{t}_{\mathrm{o}}\right)+\frac{2 \gamma}{\mathrm{r}+1}\left[\left(\frac{\mathrm{r}-1}{\mathrm{r}+1}\right)^{2}+\left(\frac{\mathrm{r}-1}{\mathrm{r}+1}\right)^{3}\right] \sigma_{\mathrm{i}}\left(\mathrm{t}-3 \mathrm{t}_{\mathrm{o}}\right), & 3 \mathrm{t}_{\mathrm{o}} \leq \mathrm{t}<5 \mathrm{t}_{\mathrm{o}} .
\end{array}
$$


The nth term for eqs (9) and (10) is

$$
\frac{2 \gamma}{r+1}\left[\left(\frac{r-1}{r+1}\right)^{n-1}+\left(\frac{r-1}{r+1}\right)^{n}\right] \sigma_{i}\left(t-n_{0}\right), \quad \text { for } n_{0} \leq t<(n+2) t_{0}
$$

where $t_{0}$ is given by eq $(8 c)$ and corresponds to one wave travel time through the sample. Therefore, $\sigma_{1}$ and $\sigma_{2}$ can easily be calculated for times greater than those given by eqs (9) and (10). We later show predictions from these models and measured stress and strain-rate histories for glass ceramic Macor ${ }^{19}$ material.

\section{Pulse Shaping}

As previously discussed, the conventional split Hopkinson pressure bar apparatus is modified by shaping the incident pulse such that the samples are in dynamic stress equilibrium and have nearly constant strain rate over most of the test duration. To achieve these ideal test conditions for brittle materials, we extend the work of Nemat-Nasser, Isaacs, and Starrett ${ }^{4}$ who used an OFHC copper disk on the impact surface of the incident bar to shape the incident pulse. In this study, we conducted experiments with both OFHC and $\mathrm{C} 11000^{18}$ copper pulse shapers and showed a superior performance by the $\mathrm{C} 11000$ materials. In particular, the $\mathrm{C} 11000$ pulse shapers could be driven to larger strains without breakup or fracture and remained more circular after deformation. We found that with both annealed and hard C11000 pulse shapers, we could obtain a broad range of strain rates for testing brittle ceramic and rock ${ }^{12}$ materials. The previous $\operatorname{model}^{4}$ was extended to accommodate the large strains obtained with the $\mathrm{C} 11000$ copper pulse 
shaper materials. In addition, we modified the equations that govern wave propagation in the striker bar to incorporate the added mass from the sabot and included elastic, rather than rigid, unloading in the pulse shaping analysis. Incident pulse model predictions are shown to be in good agreement with strain measurements.

Figure 2a shows a schematic of the impact end of the SHPB apparatus with a pulse shaper that is attached with a light coating of grease. In Fig. $2 \mathrm{a}, \rho_{\mathrm{st}}, \mathrm{c}_{\mathrm{st}}$, and $\mathrm{A}$ are the density, bar wave velocity, and cross-sectional area of the striker bar, respectively; $V_{0}$ is the striker bar

velocity at impact; and $a_{0}$ and $h_{0}$ are the initial cross-sectional area and thickness of the pulse shaper. When the striker bar impacts the pulse shaper, compressive forces are gradually transferred from the pulse shaper to the incident bar. The deformation of the pulse shaper increases its load carrying capacity by increasing its cross-sectional area and by the strain hardening of the pulse shaping material. As will be shown later, the monotonic increase of the load carrying capacity of the pulse shaper causes longer duration pulses in the incident bar.

\section{Pulse Shaping Model}

For an incompressible material and a homogeneous deformation, mass conservation gives

$$
a_{0} h_{o}=a(t) h(t)
$$

where $a(t)$ and $h(t)$ are the current cross-sectional area and thickness of the pulse shaper. The axial engineering strain in the pulse shaper is given by 


$$
\varepsilon_{\mathrm{p}}(\mathrm{t})=\frac{\mathrm{h}_{0}-\mathrm{h}(\mathrm{t})}{\mathrm{h}_{\mathrm{o}}}=1-\frac{\mathrm{h}(\mathrm{t})}{\mathrm{h}_{\mathrm{o}}}
$$

which is positive in contraction. From eqs (11) and (12), the current cross-sectional area of the pulse shaper can be written in terms of the original area and axial strain in the pulse shaper. Thus,

$$
a(t)=\frac{a_{0}}{1-\varepsilon_{p}(t)}
$$

The axial force exerted by the pulse shaper on the ends of the striker and incident bars is

$$
\mathrm{T}(\mathrm{t})=\sigma_{\mathrm{p}}(\mathrm{t}) \mathrm{a}(\mathrm{t})=\sigma_{\mathrm{i}}(\mathrm{t}) \mathrm{A}=\sigma_{\mathrm{st}}(\mathrm{t}) \mathrm{A}
$$

where $\sigma_{p}(t)$ is the true axial stress in the pulse shaper, $\sigma_{i}(t)$ is from the compressive stress wave travelling to the right in the incident bar, and $\sigma_{\mathrm{st}}(\mathrm{t})$ is from the compressive stress wave travelling to the left in the striker bar. From eq (14), the bar stresses at the pulse shaper/ bar interfaces are

$$
\sigma_{i}(\mathrm{t})=\sigma_{\mathrm{st}}(\mathrm{t})=\frac{\sigma_{\mathrm{p}}(\mathrm{t}) \mathrm{a}(\mathrm{t})}{\mathrm{A}}
$$

For now, let $\sigma_{\mathrm{p}}(\mathrm{t})$ be defined by the general form of a one-dimensional stress-strain relationship

$$
\sigma_{\mathrm{p}}=\sigma_{\mathrm{o}} \mathrm{g}\left(\varepsilon_{\mathrm{p}}\right)
$$


where $\sigma_{0}$ is a constant and $g\left(\varepsilon_{\mathrm{p}}\right)$ is a function of the pulse shaper engineering axial strain. From eqs (12), (15), and (16)

$$
\sigma_{\mathrm{i}}(\mathrm{t})=\sigma_{\mathrm{st}}(\mathrm{t})=\frac{\sigma_{\mathrm{o}} \mathrm{a}}{\mathrm{A}} \frac{\mathrm{g}\left(\varepsilon_{\mathrm{p}}\right)}{\left(1-\varepsilon_{\mathrm{p}}\right)}
$$

Since the incident and striker bars remain elastic, the axial strains in the bars at the bar/ pulse shaper interfaces can be written as

$$
\varepsilon_{\mathrm{i}}(\mathrm{t})=\varepsilon_{\mathrm{st}}(\mathrm{t})=\frac{\sigma_{\mathrm{o}} \mathrm{a}_{\mathrm{o}}}{\mathrm{EA}} \frac{\mathrm{g}\left(\varepsilon_{\mathrm{p}}\right)}{\left(1-\varepsilon_{\mathrm{p}}\right)} .
$$

The engineering strain rate in the pulse shaper is given by

$$
\dot{\varepsilon}_{\mathrm{p}}(\mathrm{t})=\frac{\mathrm{v}_{3}(\mathrm{t})-\mathrm{v}_{4}(\mathrm{t})}{\mathrm{h}_{\mathrm{o}}},
$$

where $v_{3}(t)$ and $v_{4}(t)$ are the particle velocities at the striker bar/pulse shaper (3) and incident bar/ pulse shaper (4) interfaces, respectively shown in Fig. $2 \mathrm{~b}$. From the equations that relate stress and particle velocity in the bars, $v_{3}(t)$ and $v_{4}(t)$ are given by

$$
\mathrm{v}_{3}(\mathrm{t})=\mathrm{V}_{\mathrm{o}}-\mathrm{v}_{\mathrm{st}}(\mathrm{t})=\mathrm{V}_{\mathrm{o}}-\frac{\sigma_{\mathrm{i}}(\mathrm{t})}{\rho_{\mathrm{st}} \mathrm{c}_{\mathrm{st}}}
$$




$$
\mathrm{v}_{4}(\mathrm{t})=\mathrm{v}_{\mathrm{i}}(\mathrm{t})=\frac{\sigma_{\mathrm{i}}(\mathrm{t})}{\rho \mathrm{c}}
$$

where $v_{s t}(t)$ and $v_{i}(t)$ are the particle velocities in the striker and incident bars. As shown in Figs. 1, and 2, the bar areas are equal. However, the striker bar is supported by a nylon sabot that fits into the gun barrel. As will be shown later, this sabot mass must be included in the wave analysis for the striker bar. Thus, the density and wave speed for the striker bar are denoted as $\rho_{s t}$ and $c_{s t}$, respectively.

From eqs (14), (18), and (19)

$$
\frac{\mathrm{h}_{\mathrm{o}}}{\mathrm{V}_{\mathrm{o}}} \dot{\varepsilon}_{\mathrm{p}}(\mathrm{t})=1-\mathrm{K}\left[\frac{1}{\rho \mathrm{c}}+\frac{1}{\rho_{\mathrm{st}} \mathrm{c}_{\mathrm{st}}}\right] \frac{\mathrm{g}\left(\varepsilon_{\mathrm{p}}\right)}{1-\varepsilon_{\mathrm{p}}} \text {, for } 0 \leq \mathrm{t}<\tau
$$

which has a solution

$$
\begin{gathered}
\mathrm{t}=\frac{\mathrm{h}_{\mathrm{o}}}{\mathrm{V}_{\mathrm{o}}} \int_{0}^{\varepsilon_{\mathrm{p}}}\left[1-\mathrm{K}\left[\frac{1}{\rho \mathrm{c}}+\frac{1}{\rho_{\mathrm{st}} \mathrm{c}_{\mathrm{st}}}\right] \frac{\mathrm{g}(\mathrm{x})}{(1-\mathrm{x})}\right]^{-1} \mathrm{dx}, \text { for } 0 \leq \mathrm{t}<\tau \\
\mathrm{K}=\frac{\sigma_{\mathrm{o}} \mathrm{a}_{\mathrm{o}}}{\mathrm{AV} \mathrm{V}_{\mathrm{o}}}, \quad \text { and } \tau=\frac{2 \mathrm{~L}}{\mathrm{c}_{\mathrm{st}}}
\end{gathered}
$$

where $\tau$ is equal to two wave transit times in the striker bar. Once $\varepsilon_{p}(t)$ is calculated from eq (21a), the strain in the incident bar can be obtained from eq (17b). In addition, eq (21a) is valid only as long as the pulse shaper does not expand beyond the bar surfaces. Equation (13) shows 
that the engineering strain in the pulse shaper is limited for a given initial pulse shaper area $a_{0}$, such that $\mathrm{a}(\mathrm{t}) \leq \mathrm{A}$.

Equation (21a) does not explicitly give values for strain in the pulse shaper as a function of time for $0 \leq \mathrm{t}<\tau$. However, we can obtain closed-form equations for some of the features of the $\varepsilon_{\mathrm{p}}$ versus $\mathrm{t}$ curve. For small enough values of $\varepsilon_{\mathrm{p}}$, the second term in eq (20) can be neglected and

$$
\varepsilon_{\mathrm{p}} \approx \frac{\mathrm{V}_{\mathrm{o}} \mathrm{t}}{\mathrm{h}_{\mathrm{o}}} \text { for } \mathrm{t}<<1
$$

Also, the integral in eq (21a) must remain positive because time is always positive. Thus, the largest value of strain in the pulse shaper $\varepsilon_{\mathrm{pm}}$ is given by

$$
\frac{\mathrm{g}\left(\varepsilon_{\mathrm{pm}}\right)}{\left(1-\varepsilon_{\mathrm{pm}}\right)}=\frac{1}{\mathrm{~K}\left[\frac{1}{\rho \mathrm{c}}+\frac{1}{\rho_{\mathrm{st}} \mathrm{c}_{\mathrm{st}}}\right]}
$$

From eqs (17a) and (22b) the maximum possible stress in the incident bar is given by

$$
\sigma_{\mathrm{im}}=\frac{\mathrm{V}_{\mathrm{o}}}{\left[\frac{1}{\rho \mathrm{c}}+\frac{1}{\rho_{\mathrm{st}} \mathrm{c}_{\mathrm{st}}}\right]} .
$$

Equation (22c) gives the value of incident stress for the problem without a pulse shaper. So if 
the striker bar is long enough, the stress in the incident bar will approach but not exceed $\sigma_{\text {im }}$ given by $(22 \mathrm{c})$.

We now examine the pulse shaper response for $\tau \leq t<2 \tau$. At $t=\tau / 2$, the compressive wave travelling to the left in the striker bar shown in Fig. $2 \mathrm{~b}$ reaches the free surface and reflects as a tensile pulse travelling to the right. At $t=\tau$, this right travelling tensile pulse reaches the striker bar/ pulse shaper interface and causes additional reflected and transmitted waves to propagate in the striker and incident bars. We define $-\sigma_{\mathrm{st}}(\mathrm{t}-\tau)$ as the interface stress from the right travelling tensile pulse. The additional reflected and transmitted interface stresses are defined as $\sigma_{\mathrm{r}}{ }^{1}(\mathrm{t}-\tau)$ and $\sigma_{\mathrm{t}}{ }^{1}(\mathrm{t}-\tau)$, respectively. Thus, the axial force in the pulse shaper is given by

$$
\begin{aligned}
\mathrm{T}(\mathrm{t})=\sigma_{\mathrm{p}}(\mathrm{t}) \mathrm{a}(\mathrm{t}) & =\left[\sigma_{\mathrm{i}}(\mathrm{t})+\sigma_{\mathrm{t}}{ }^{1}(\mathrm{t}-\tau)\right] \mathrm{A} \\
& =\left[\sigma_{\mathrm{st}}(\mathrm{t})-\sigma_{\mathrm{st}}(\mathrm{t}-\tau)+\sigma_{\mathrm{r}}{ }^{1}(\mathrm{t}-\tau)\right] \mathrm{A}
\end{aligned}
$$

Particle velocities at the pulse shaper/ bar interfaces shown in Fig. $2 b$ are

$$
\begin{aligned}
\mathrm{v}_{3}(\mathrm{t}) & =\mathrm{V}_{\mathrm{o}}-\mathrm{v}_{\mathrm{st}}(\mathrm{t})-\mathrm{v}_{\mathrm{st}}(\mathrm{t}-\tau)-\mathrm{v}_{\mathrm{r}}{ }^{1}(\mathrm{t}-\tau) \\
& =\mathrm{V}_{\mathrm{o}}-\frac{\sigma_{\mathrm{st}}(\mathrm{t})}{\rho_{\mathrm{st}} \mathrm{c}_{\mathrm{st}}}-\frac{\sigma_{\mathrm{st}}(\mathrm{t}-\tau)}{\rho_{\mathrm{st}} \mathrm{c}_{\mathrm{st}}}-\frac{\sigma_{\mathrm{r}}{ }^{1}(\mathrm{t}-\tau)}{\rho_{\mathrm{st}} \mathrm{c}_{\mathrm{st}}} \\
\mathrm{v}_{4}(\mathrm{t}) & =\mathrm{v}_{\mathrm{i}}(\mathrm{t})+\mathrm{v}_{\mathrm{t}}{ }^{1}(\mathrm{t}-\tau)=\frac{\sigma_{\mathrm{i}}(\mathrm{t})}{\rho \mathrm{c}}+\frac{\sigma_{\mathrm{t}}{ }^{1}(\mathrm{t}-\tau)}{\rho \mathrm{c}} .
\end{aligned}
$$

From eqs (18), (23), and (24), the engineering strain rate is 


$$
\mathrm{h}_{\mathrm{o}} \dot{\varepsilon}_{\mathrm{p}}(\mathrm{t})=\mathrm{V}_{\mathrm{o}}-\frac{\sigma_{\mathrm{st}}(\mathrm{t})}{\rho_{\mathrm{st}} \mathrm{c}_{\mathrm{st}}}-\frac{\sigma_{\mathrm{st}}(\mathrm{t}-\tau)}{\rho_{\mathrm{st}} \mathrm{c}_{\mathrm{st}}}-\frac{\sigma_{\mathrm{r}}{ }^{\prime}(\mathrm{t}-\tau)}{\rho_{\mathrm{st}} \mathrm{c}_{\mathrm{st}}}-\frac{\sigma_{\mathrm{i}}(\mathrm{t})}{\rho \mathrm{c}}-\frac{\sigma_{\mathrm{t}}{ }^{\prime}(\mathrm{t}-\tau)}{\rho \mathrm{c}}
$$

Now, we solve for $\sigma_{\mathrm{r}}{ }^{1}(\mathrm{t}-\tau)$ from eq (23) and eliminate $\sigma_{\mathrm{r}}{ }^{1}(\mathrm{t}-\tau)$ from eq (25). Thus,

$$
\mathrm{h}_{\mathrm{o}} \dot{\varepsilon}_{\mathrm{p}}(\mathrm{t})=\mathrm{V}_{\mathrm{o}}-\left[\frac{1}{\rho \mathrm{c}}+\frac{1}{\rho_{\mathrm{st}} \mathrm{c}_{\mathrm{st}}}\right]\left[\sigma_{\mathrm{i}}(\mathrm{t})+\sigma_{\mathrm{t}}{ }^{1}(\mathrm{t}-\tau)\right]-\frac{2 \sigma_{\mathrm{st}}(\mathrm{t}-\tau)}{\rho_{\mathrm{st}} \mathrm{c}_{\mathrm{st}}}
$$

From eqs (23), (16), and (13), the stress in the incident bar is

$$
\sigma_{\mathrm{i}}(\mathrm{t})+\sigma_{\mathrm{t}}^{\prime}(\mathrm{t}-\tau)=\frac{\sigma_{\mathrm{p}}(\mathrm{t}) \mathrm{a}(\mathrm{t})}{\mathrm{A}}=\frac{\sigma_{\mathrm{o}} \mathrm{g}\left(\varepsilon_{\mathrm{p}}\right)}{\left(1-\varepsilon_{\mathrm{p}}\right)} \frac{\mathrm{a}_{\mathrm{o}}}{\mathrm{A}}
$$

and from eq (17a)

$$
\sigma_{\mathrm{st}}(\mathrm{t}-\tau)=\frac{\sigma_{\mathrm{o}} \mathrm{g}\left(\varepsilon_{\mathrm{p}}(\mathrm{t}-\tau)\right)}{\left(1-\varepsilon_{\mathrm{p}}(\mathrm{t}-\tau)\right)} \frac{\mathrm{a}_{\mathrm{o}}}{\mathrm{A}} .
$$

Finally, we substitute eqs (27) and (28) into eq (26) and obtain

$$
\frac{\mathrm{h}_{\mathrm{o}}}{\mathrm{V}_{\mathrm{o}}} \dot{\varepsilon}_{\mathrm{p}}(\mathrm{t})=1-\mathrm{K}\left[\frac{1}{\rho \mathrm{c}}+\frac{1}{\rho_{\mathrm{st}} \mathrm{c}_{\mathrm{st}}}\right] \frac{\mathrm{g}\left(\varepsilon_{\mathrm{p}}\right)}{1-\varepsilon_{\mathrm{p}}}-\frac{2 \mathrm{~K}}{\rho_{\mathrm{st}} \mathrm{c}_{\mathrm{st}}} \frac{\mathrm{g}\left(\varepsilon_{\mathrm{p}}(\mathrm{t}-\tau)\right)}{1-\varepsilon_{\mathrm{p}}(\mathrm{t}-\tau)} \text {, for } \tau \leq \mathrm{t}<2 \tau \text {. }
$$

The solution to eq (29) is 


$$
\mathrm{t}=\tau+\frac{\mathrm{h}_{\mathrm{o}}}{\mathrm{V}_{\mathrm{o}}} \int_{\varepsilon_{\mathrm{p}}}^{\varepsilon_{\mathrm{p}}}\left[1-\mathrm{K}\left[\frac{1}{\rho \mathrm{c}}+\frac{1}{\rho_{\mathrm{st}} \mathrm{c}_{\mathrm{st}}}\right] \frac{\mathrm{g}(\mathrm{x})}{1-\mathrm{x}}-\frac{2 \mathrm{~K}}{\rho_{\mathrm{st}} \mathrm{c}_{\mathrm{st}}} \frac{\mathrm{g}\left(\varepsilon_{\mathrm{p}}(\mathrm{t}-\tau)\right)}{1-\varepsilon_{\mathrm{p}}(\mathrm{t}-\tau)}\right]^{-1} \mathrm{dx}
$$

for $\tau \leq \mathrm{t}<2 \tau$,

where $\varepsilon_{p}{ }^{1}$ is the strain in the pulse shaper at $t=\tau, \varepsilon_{p}(t-\tau)$ is calculated from eq (21a) with the appropriate time shift, and $\mathrm{K}$ and $\tau$ are defined by eq (21b).

Equation (30) gives the total strain in the pulse shaper for $\tau \leq t<2 \tau$. The strain in the incident bar is calculated from eq (17b) using the values of $\varepsilon_{p}$ for $\tau \leq t<2 \tau$ calculated from eq (30). As previously mentioned, the pulse shaper must not expand beyond the bar surfaces, so the engineering strain in the pulse shaper is limited by eq (13) for an initial pulse shaper area $a_{0}$, such that $\mathrm{a}(\mathrm{t}) \leq \mathrm{A}$. In addition, eqs (29) and (30) are valid only if the pulse shaper remains in contraction or $\dot{\varepsilon}_{\mathrm{p}}(\mathrm{t})$ remains positive in eq $(18)$. Thus for the particle velocities shown in Fig. $2 b,\left(v_{3}-v_{4}\right) \geq 0$. When $v_{3}<v_{4}$, the pulse shaper will be modeled as elastic unloading.

As long as a $<A$ and $v_{3}>v_{4}$, the pulse shaper continues to deform in compression. We repeated the previous analyses for multiple reverberations in the striker bar. For $t>2 \tau$, the general versions of eqs (26) and (29) are

$$
\begin{aligned}
& \mathrm{h}_{\mathrm{o}} \dot{\varepsilon}_{\mathrm{p}}(\mathrm{t})=\mathrm{V}_{\mathrm{o}}-\left[\frac{1}{\rho \mathrm{c}}+\right.\left.\frac{1}{\rho_{\mathrm{st}} \mathrm{c}_{\mathrm{st}}}\right]\left[\sigma_{\mathrm{i}}(\mathrm{t})+\sigma_{\mathrm{t}}{ }^{1}(\mathrm{t}-\tau)+\sigma_{\mathrm{t}}{ }^{2}(\mathrm{t}-2 \tau)+\ldots \ldots \sigma_{\mathrm{t}}{ }^{\mathrm{n}}(\mathrm{t}-\mathrm{n} \tau)\right] \\
&-\frac{2}{\rho_{\mathrm{st}} \mathrm{c}_{\mathrm{st}}}\left[\sigma_{\mathrm{st}}(\mathrm{t}-\tau)+\sigma_{\mathrm{r}}{ }^{1}(\mathrm{t}-2 \tau)+\sigma_{\mathrm{r}}{ }^{2}(\mathrm{t}-3 \tau)+\ldots . \sigma_{\mathrm{r}}{ }^{(\mathrm{n}-1)}(\mathrm{t}-\mathrm{n} \tau)\right] \\
& \quad \text { for } \mathrm{n} \tau \leq \mathrm{t}<(\mathrm{n}+1) \tau .
\end{aligned}
$$

and 


$$
\begin{aligned}
\frac{\mathrm{h}_{\mathrm{o}}}{\mathrm{V}_{\mathrm{o}}} \dot{\varepsilon}_{\mathrm{p}}(\mathrm{t})=1-\mathrm{K}\left[\frac{1}{\rho \mathrm{c}}+\frac{1}{\rho_{\mathrm{st}} \mathrm{c}_{\mathrm{st}}}\right] \frac{\mathrm{g}\left(\varepsilon_{\mathrm{p}}\right)}{1-\varepsilon_{\mathrm{p}}} & \\
\quad-\frac{2 \mathrm{~K}}{\rho_{\mathrm{st}} \mathrm{c}_{\mathrm{st}}}\left[\frac{\mathrm{g}\left(\varepsilon_{\mathrm{p}}(\mathrm{t}-\tau)\right)}{1-\varepsilon_{\mathrm{p}}(\mathrm{t}-\tau)}+\frac{\mathrm{g}\left(\varepsilon_{\mathrm{p}}(\mathrm{t}-2 \tau)\right)}{1-\varepsilon_{\mathrm{p}}(\mathrm{t}-2 \tau)}+\ldots . \frac{\mathrm{g}\left(\varepsilon_{\mathrm{p}}(\mathrm{t}-\mathrm{n} \tau)\right)}{1-\varepsilon_{\mathrm{p}}(\mathrm{t}-\mathrm{n} \tau)}\right], & \quad \text { for } \mathrm{n} \tau \leq \mathrm{t}<(\mathrm{n}+1) \tau .
\end{aligned}
$$

Now consider the situation when $\mathrm{v}_{3} \leq \mathrm{v}_{4}$ and the pulse shaper unloads during $\tau \leq \mathrm{t}<2 \tau$ at $\mathrm{t}=\mathrm{t}^{*}$. We assume the pulse shaper unloads elastically and that the unloading stress is given by

$$
\sigma_{\mathrm{u}}(\mathrm{t})=\sigma_{\mathrm{p}}^{*}-\mathrm{E}_{\mathrm{p}}\left(\varepsilon_{\mathrm{p}}^{*}-\varepsilon_{\mathrm{p}}\right)
$$

where $\sigma_{\mathrm{p}}{ }^{*}, \varepsilon_{\mathrm{p}}{ }^{*}$ are the peak stress and strain at $\mathrm{t}=\mathrm{t}^{*}$ when $\mathrm{v}_{3}=\mathrm{v}_{4}$, and $\mathrm{E}_{\mathrm{p}}$ is the unloading Young's modulus.

Equation (26) gives the strain rate of the pulse shaper in terms of stress components in the incident and transmission bars for $\tau \leq \mathrm{t}<2 \tau$. For $\tau \leq \mathrm{t}<\mathrm{t}^{*}$, the stress in the incident bar at the pulse shaper/ incident bar interface is given by eq (27). However, for $t^{*} \leq t<2 \tau$, the pulse shaper is unloading. From a force balance at the pulse shaper/ incident bar interface, the stress in the incident bar is

$$
\sigma_{\mathrm{i}}(\mathrm{t})+\sigma_{\mathrm{t}}{ }^{1}(\mathrm{t}-\tau)=\frac{\mathrm{a}_{\mathrm{o}} \sigma_{\mathrm{u}}(\mathrm{t})}{\mathrm{A}\left(1-\varepsilon_{\mathrm{p}}\right)}, \text { for } \mathrm{t}^{*} \leq \mathrm{t}<2 \tau
$$

Equation (34) assumes that the stress-strain law for the pulse shaper is given by eq (33) and that $\sigma_{\mathrm{u}}(\mathrm{t}) \leq \sigma_{\mathrm{p}}{ }^{*}$. The last term in eq (26) is the interface stress from the right travelling tensile pulse 
coming from the free surface of the striker bar. Since this stress component is delayed by $t=\tau$, $\sigma_{\mathrm{st}}(\mathrm{t}-\tau)$ is given by eq (28). We substitute eqs (28) and (34) into eq (26) and obtain

$$
\begin{aligned}
& \frac{\mathrm{h}_{\mathrm{o}}}{\mathrm{V}_{\mathrm{o}}} \dot{\varepsilon}_{\mathrm{p}}(\mathrm{t})=1-\mathrm{K}\left[\frac{1}{\rho \mathrm{c}}+\frac{1}{\rho_{\mathrm{st}} \mathrm{c}_{\mathrm{st}}}\right] \frac{\sigma_{\mathrm{p}}^{*}-\mathrm{E}_{\mathrm{p}}\left(\varepsilon_{\mathrm{p}}{ }^{*}-\varepsilon_{\mathrm{p}}\right)}{\sigma_{\mathrm{o}}\left(1-\varepsilon_{\mathrm{p}}\right)}-\frac{2 \mathrm{~K}}{\rho_{\mathrm{st}} \mathrm{c}_{\mathrm{st}}} \frac{\mathrm{g}\left(\varepsilon_{\mathrm{p}}(\mathrm{t}-\tau)\right)}{1-\varepsilon_{\mathrm{p}}(\mathrm{t}-\tau)}, \\
& \text { for } t^{*} \leq t<2 \tau
\end{aligned}
$$

which has solution

$$
\begin{array}{r}
\mathrm{t}=\mathrm{t}^{*}+\frac{\mathrm{h}_{\mathrm{o}}}{\mathrm{V}_{\mathrm{o}}} \int_{\varepsilon_{\mathrm{p}}^{*}}^{\varepsilon_{\mathrm{p}}}\left[1-\mathrm{K}\left[\frac{1}{\rho \mathrm{c}}+\frac{1}{\rho_{\mathrm{st}} \mathrm{c}_{\mathrm{st}}}\right] \frac{\sigma_{\mathrm{p}}^{*}-\mathrm{E}_{\mathrm{p}}\left(\varepsilon_{\mathrm{p}}{ }^{*}-\mathrm{x}\right)}{\sigma_{\mathrm{o}}(1-\mathrm{x})}-\frac{2 \mathrm{~K}}{\rho_{\mathrm{st}} \mathrm{c}_{\mathrm{st}}} \frac{\mathrm{g}\left(\varepsilon_{\mathrm{p}}(\mathrm{t}-\tau)\right)}{1-\varepsilon_{\mathrm{p}}(\mathrm{t}-\tau)}\right]^{-1} \mathrm{dx}, \\
\text { for } \mathrm{t}^{*} \leq \mathrm{t}<2 \tau
\end{array}
$$

where $t^{*}$ is the time when $v_{3}=v_{4}$ and unloading begins.

For many cases, additional wave reverberations in the striker bar are required to completely unload the pulse shaper. We repeated the previous analysis and obtained equations for the pulse shaper response for the onset of unloading between $\tau \leq t<2 \tau$ and responses during $2 \tau \leq \mathrm{t}<3 \tau$. Thus,

$$
\begin{gathered}
\frac{\mathrm{h}_{\mathrm{o}}}{\mathrm{V}_{\mathrm{o}}} \dot{\varepsilon}_{\mathrm{p}}(\mathrm{t})=1-\mathrm{K}\left[\frac{1}{\rho \mathrm{c}}+\frac{1}{\rho_{\mathrm{st}} \mathrm{c}_{\mathrm{st}}}\right] \frac{\sigma_{\mathrm{p}}{ }^{*}-\mathrm{E}_{\mathrm{p}}\left(\varepsilon_{\mathrm{p}}{ }^{*}-\varepsilon_{\mathrm{p}}\right)}{\sigma_{\mathrm{o}}\left(1-\varepsilon_{\mathrm{p}}\right)}-\frac{2 \mathrm{~K}}{\rho_{\mathrm{st}} \mathrm{c}_{\mathrm{st}}} \frac{\mathrm{g}\left(\varepsilon_{\mathrm{p}}(\mathrm{t}-\tau)\right)}{1-\varepsilon_{\mathrm{p}}(\mathrm{t}-\tau)}- \\
\frac{2 \mathrm{~K}}{\rho_{\mathrm{st}} \mathrm{c}_{\mathrm{st}}} \frac{\mathrm{g}\left(\varepsilon_{\mathrm{p}}(\mathrm{t}-2 \tau)\right)}{1-\varepsilon_{\mathrm{p}}(\mathrm{t}-2 \tau)}, \quad \text { for } 2 \tau \leq \mathrm{t}<\tau+\mathrm{t} *
\end{gathered}
$$




$$
\begin{array}{rr}
\frac{\mathrm{h}_{\mathrm{o}}}{\mathrm{V}_{\mathrm{o}}} \dot{\varepsilon}_{\mathrm{p}}(\mathrm{t})=1-\mathrm{K}\left[\frac{1}{\rho \mathrm{c}}+\frac{1}{\rho_{\mathrm{st}} \mathrm{c}_{\mathrm{st}}}\right] \frac{\sigma_{\mathrm{p}}{ }^{*}-\mathrm{E}_{\mathrm{p}}\left(\varepsilon_{\mathrm{p}}{ }^{*}-\varepsilon_{\mathrm{p}}\right)}{\sigma_{\mathrm{o}}\left(1-\varepsilon_{\mathrm{p}}\right)}-\frac{2 \mathrm{~K}}{\rho_{\mathrm{st}} \mathrm{c}_{\mathrm{st}}} \frac{\sigma_{\mathrm{p}}{ }^{*}-\mathrm{E}_{\mathrm{p}}\left(\varepsilon_{\mathrm{p}}{ }^{*}-\varepsilon_{\mathrm{p}}(\mathrm{t}-\tau)\right)}{\sigma_{\mathrm{o}}\left(1-\varepsilon_{\mathrm{p}}(\mathrm{t}-\tau)\right)}- \\
\frac{2 \mathrm{~K}}{\rho_{\mathrm{st}} \mathrm{c}_{\mathrm{st}}} \frac{\mathrm{g}\left(\varepsilon_{\mathrm{p}}(\mathrm{t}-2 \tau)\right)}{1-\varepsilon_{\mathrm{p}}(\mathrm{t}-2 \tau)}, \quad \text { for } \tau+\mathrm{t}^{*} \leq \mathrm{t}<3 \tau .
\end{array}
$$

Two response equations for $2 \tau \leq t<3 \tau$ are required because of time delay terms in eq (31) that correspond to reverberations in the striker bar. In particular, the third terms in eqs (37a) and (37b) are different and the other terms are the same. For $t \leq t *$ the pulse shaper is loading and eq (16) applies. By contrast, for $t \geq t *$ the pulse shaper is unloading and eq (33) applies.

For the situation where the pulse shaper is not fully unloaded at $t=3 \tau$, we again repeated the previous analysis and obtained equations for the pulse shaper response for unloading between $\tau \leq \mathrm{t}<2 \tau$ and responses during $3 \tau \leq \mathrm{t}<4 \tau$. Thus,

$$
\begin{aligned}
& \frac{\mathrm{h}_{o}}{\mathrm{~V}_{\mathrm{o}}} \dot{\varepsilon}_{\mathrm{p}}(\mathrm{t})=1-\mathrm{K}\left[\frac{1}{\rho \mathrm{c}}+\frac{1}{\rho_{\mathrm{st}} \mathrm{c}_{\mathrm{st}}}\right] \frac{\sigma_{\mathrm{p}}^{*}-\mathrm{E}_{\mathrm{p}}\left(\varepsilon_{\mathrm{p}}{ }^{*}-\varepsilon_{\mathrm{p}}\right)}{\sigma_{\mathrm{o}}\left(1-\varepsilon_{\mathrm{p}}\right)}- \\
& \frac{2 \mathrm{~K}}{\rho_{\mathrm{st}} \mathrm{c}_{\mathrm{st}}}\left[\frac{{\sigma_{\mathrm{p}}}^{*}-\mathrm{E}_{\mathrm{p}}\left(\varepsilon_{\mathrm{p}}^{*}-\varepsilon_{\mathrm{p}}(\mathrm{t}-\tau)\right)}{\sigma_{\mathrm{o}}\left(1-\varepsilon_{\mathrm{p}}(\mathrm{t}-\tau)\right)}+\frac{\mathrm{g}\left(\varepsilon_{\mathrm{p}}(\mathrm{t}-2 \tau)\right)}{1-\varepsilon_{\mathrm{p}}(\mathrm{t}-2 \tau)}+\frac{\mathrm{g}\left(\varepsilon_{\mathrm{p}}(\mathrm{t}-3 \tau)\right)}{1-\varepsilon_{\mathrm{p}}(\mathrm{t}-3 \tau)}\right] \text {, } \\
& \text { for } 3 \tau \leq t<2 \tau+t * \\
& \frac{\mathrm{h}_{\mathrm{o}}}{\mathrm{V}_{\mathrm{o}}} \dot{\varepsilon}_{\mathrm{p}}(\mathrm{t})=1-\mathrm{K}\left[\frac{1}{\rho \mathrm{c}}+\frac{1}{\rho_{\mathrm{st}} \mathrm{c}_{\mathrm{st}}}\right] \frac{\sigma_{\mathrm{p}}^{*}-\mathrm{E}_{\mathrm{p}}\left(\varepsilon_{\mathrm{p}}^{*}-\varepsilon_{\mathrm{p}}\right)}{\sigma_{\mathrm{o}}\left(1-\varepsilon_{\mathrm{p}}\right)}- \\
& \frac{2 \mathrm{~K}}{\rho_{\mathrm{st}} \mathrm{c}_{\mathrm{st}}}\left[\frac{\sigma_{\mathrm{p}}{ }^{*}-\mathrm{E}_{\mathrm{p}}\left(\varepsilon_{\mathrm{p}}{ }^{*}-\varepsilon_{\mathrm{p}}(\mathrm{t}-\tau)\right)}{\sigma_{\mathrm{o}}\left(1-\varepsilon_{\mathrm{p}}(\mathrm{t}-\tau)\right)}+\frac{\sigma_{\mathrm{p}}{ }^{*}-\mathrm{E}_{\mathrm{p}}\left(\varepsilon_{\mathrm{p}}{ }^{*}-\varepsilon_{\mathrm{p}}(\mathrm{t}-2 \tau)\right)}{\sigma_{\mathrm{o}}\left(1-\varepsilon_{\mathrm{p}}(\mathrm{t}-2 \tau)\right)}+\frac{\mathrm{g}\left(\varepsilon_{\mathrm{p}}(\mathrm{t}-3 \tau)\right)}{1-\varepsilon_{\mathrm{p}}(\mathrm{t}-3 \tau)}\right] \text {, } \\
& \text { for } 2 \tau+t^{*} \leq t<4 \tau \text {. }
\end{aligned}
$$


Numerical evaluations helped us understand the elastic unloading process that starts when $v_{3}=v_{4}$ and continues for $v_{4}>v_{3}$ (see Fig. 2b). We found that the terms corresponding to the striker impact dominated values of $v_{3}$ and $v_{4}$. For example, the dominant term in eq (24a) for $v_{3}(t)$ is $v_{s t}(t)=\sigma_{s t}(t) / \rho_{s t} c_{s t}$ and the dominant term in eq $(24 b)$ for $v_{4}(t)$ is $v_{i}(t)=\sigma_{i}(t) / \rho c$. As the pulse shaper stress decreases during unloading, $\sigma_{s t}(t)$ and $\sigma_{i}(t)$ decreases rapidly which also causes $v_{3}$ and $v_{4}$ to decrease rapidly. As $\sigma_{s t}(t)$ and $\sigma_{i}(t)$ decrease, $v_{3}(t)$ decreases much more slowly than $\mathrm{v}_{4}(\mathrm{t})$. For some cases, the unloading condition $\mathrm{v}_{3}(\mathrm{t}) \leq \mathrm{v}_{4}(\mathrm{t})$ may be violated and the pulse shaper will begin elastic loading. Due to the heavy dependence of $\sigma_{i}(t)$. on $v_{4}(t)$, this reloading is short lived, occurs frequently, and is a main reason why it is not uncommon for the unloading of the pulse shaper to be long $(\sim 100 \mu \mathrm{s})$. The unload/reload cycles in the pulse shaper eventually reduce the pulse shaper stress to zero and the striker and incident bars separate from each another.

In summary, we have presented a pulse shaping model for loading and unloading of the pulse shaper material. The pulse shaper material is taken as incompressible and assumed to undergo homogeneous deformation. Loading is governed by a general, one-dimensional stressstrain relationship (eq (16)) and unloading is taken as linear (eq (33)). A general loading equation for multiple reverberations in the striker bar is developed and given by eq (32). The

unloading procedure is more complicated and only the case for unloading at $t^{*}$ between $\tau \leq t<$ $2 \tau$ is presented. For other cases where unloading starts at times greater than $2 \tau$, we developed a Fortran computer code ${ }^{20}$ to calculate the pulse shaper response.

\section{Pulse Shaper Material Response}

We conducted experiments with both OFHC and $\mathrm{C} 11000^{18}$ copper pulse shapers and 
showed that the $\mathrm{C} 11000$ pulse shapers could be driven to larger strains without breakup and remained more circular after deformation. In addition, we present results for both hard and annealed $\mathrm{C} 11000$ copper. The hard copper was received from the supplier and measured 45 on the Rockwell $\mathrm{B}$ scale (HRB 45). We heated the as-received copper for 2 hours at $800^{\circ} \mathrm{F}$ to obtain the annealed copper.

The original pulse shaper geometries had thicknesses ranging from $0.8 \mathrm{~mm}$ to $1.6 \mathrm{~mm}$ and thickness-to-diameter ratios ranging from 0.16 to 0.50 . As discussed by Kolsky ${ }^{1}$, Davies and Hunter $^{21}$, and Baron ${ }^{22}$, these geometries can create a complicated two-dimensional stress-state in the pulse shapers due to inertial and frictional effects. However, we are only attempting to produce a desired strain-time pulse in the incident bar and are not attempting to obtain stressstrain data for the pulse shapers. Thus $\sigma_{\mathrm{p}}=\sigma_{\mathrm{o}} \mathrm{g}\left(\varepsilon_{\mathrm{p}}\right)$ given by eq (16) should not be construed as a constitutive material description of the pulse shaper, but as a one-dimensional resistance function.

For the hard and annealed, C11000 copper pulse shapers, we determined that a resistance function of the form

$$
\sigma_{\mathrm{p}}=\frac{\sigma_{\mathrm{o}} \varepsilon_{\mathrm{p}}^{\mathrm{n}}}{1-\varepsilon_{\mathrm{p}}^{\mathrm{m}}}
$$

could accurately curve fit our data with $\sigma_{0}, \mathrm{n}$, and $\mathrm{m}$ as adjustable parameters. Figure 3 shows the hard copper $(\mathrm{HRB} 45)$ resistance function with $\sigma_{0}=550 \mathrm{MPa}, \mathrm{n}=0.0875$, and $\mathrm{m}=4.0$. The dashed lines are split Hopkinson pressure bar data from samples with an original diameter of $9.52 \mathrm{~mm}$ and an original thickness of $6.4 \mathrm{~mm}$. These data reached engineering strain magnitudes 
of 0.44 and 0.47 with strain rates of 3,200 and $3,500 \mathrm{~s}^{-1}$, respectively. The data points in Fig. 3 are from pulse shaping experiments where we used an end-point method. For each data point in Fig. 3 the engineering strain is the final strain calculated from eq (12). From eqs (13) and (14), the true axial stress in the pulse shaper can be expressed in terms of strain in the incident bar as

$$
\sigma_{p}=\frac{E A}{a_{o}}\left(1-\varepsilon_{p}\right) \cdot \varepsilon_{i}
$$

The corresponding true axial stress for each data point in Fig. 3 is that value corresponding to the maximum strain measured with the incident bar. Thus, maximum strain is obtained from a posttest thickness measurement, and maximum stress is calculated from eq (40) with the maximum measured strain in the incident bar. Figure 3 shows that the end-point data and Hopkinson bar data are in good agreement to strains of about 0.45 . The end-point method was required to obtain strain data to about 0.85 .

Figure 4 shows resistance functions for 0.79 and 1.29 -mm-thick annealed copper pulse shapers. The resistance function for the 0.79 -mm-thick pulse shapers lies above that for the 1.29-mm-thick pulse shapers and that suggests a slight rate effect for the material response. The parameters in eq (39) for the annealed pulse shapers with original thickness $h_{0}=0.79 \mathrm{~mm}$ are $\sigma_{0}$ $=750 \mathrm{MPa}, \mathrm{n}=0.37$, and $\mathrm{m}=4.25 ;$ for $\mathrm{h}_{0}=1.29 \mathrm{~mm}$, the parameters are $\sigma_{0}=625 \mathrm{MPa}, \mathrm{n}=$ 0.32 , and $\mathrm{m}=4.25$. In addition, we present results from five Hopkinson bar experiments. The data with permanent strains of 0.13 , and $0.18 \mathrm{had}$ an original diameter of $9.53 \mathrm{~mm}$, an original thickness of $12.70 \mathrm{~mm}$, and strain rates of 2,100 , and $3,000 \mathrm{~s}^{-1}$, respectively. The Hopkinson bar data with a permanent strain of 0.25 had an original diameter of $9.53 \mathrm{~mm}$, an original thickness of $6.35 \mathrm{~mm}$, and strain rate of $4,370 \mathrm{~s}^{-1}$; whereas, the Hopkinson bar data with permanent strains 
of 0.36 , and 0.54 , had an original diameter and thickness of $6.35 \mathrm{~mm}$, and strain rates of $5,800 \mathrm{~s}^{-1}$ each. The end-point method data points for the 1.29 -mm-thick pulse shapers are in close agreement with the Hopkinson bar data for strains to 0.55 . Again, the end-point method was required to obtain strain data to about 0.85 .

\section{Incident Strain from Pulse Shaped Experiments}

We modified the split Hopkinson pressure bar apparatus by shaping the incident pulses such that test samples are in dynamic stress equilibrium and have a nearly constant strain rate over most of the test duration. To obtain reliable dynamic, stress-strain data for brittle materials such as rocks or ceramics that have failure strains less than a few percent, the incident strain pulse should have a linear or quasi-linear rise. We have already used the pulse shaping techniques described in this work to conduct experiments with limestone samples ${ }^{12}$ and will show another example with a machineable glass ceramic in the next section.

Figures 5 and 6 show data and model predictions for incident stresses from pulse shaped experiments with hard (HRB 45) and annealed C11000 pulse shapers, respectively: The pulse shapers had original thicknesses and diameters of $1.6 \mathrm{~mm}$ and $4.8 \mathrm{~mm}$, respectively. The 12.7mm-diameter striker and incident bars shown in Fig. 2a had lengths of 152 and $2130 \mathrm{~mm}$, respectively. The bars were made from high strength maraging VM350 steel (Vasco Pacific, Montebello, CA) and have density $\rho=8100 \mathrm{~kg} / \mathrm{m}^{3}$, Young's modulus $\mathrm{E}=200 \mathrm{GPa}$, and bar wave velocity $c=4970 \mathrm{~m} / \mathrm{s}$. The strain gages shown in Fig. 2a are located at $1060 \mathrm{~mm}$ from the impact surface on the incident bar.

The striker bar is launched by a gas gun that has a bore diameter larger than the striker bar diameter, so the striker bar is fitted with two nylon bore-riders (sabots). The bore-riders are 
nylon cylinders that make a snug fit for the striker bar in the gun bore and provide a good alignment for projectile launch. We learned early in this study that the added mass of the boreriders needed to be included in the striker bar wave analysis for predicting incident strain pulses. This added mass is included in the derivation of the elementary theory for the striker bar by using an effective density $\rho_{\mathrm{st}}$, where $\rho_{\mathrm{st}}$ is the total mass of the striker bar and bore-riders divided by the volume of the striker bar. The wave velocity for the striker bar is taken as $c_{s t}{ }^{2}=E / \rho_{s t}$, where E is Young's Modulus for the striker bar. Model predictions and measured strain pulses are in good agreement with this approximation.

We previously defined $\tau$ with eq (21b) as the time for two wave transit times in a striker bar of length L. For the data and model predictions shown in Figs. 5 and 6, the experiments were conducted with $\rho_{\mathrm{st}}=8,750 \mathrm{~kg} / \mathrm{m}^{3}, \mathrm{c}_{\mathrm{st}}=4,780 \mathrm{~m} / \mathrm{s}, \mathrm{L}=152 \mathrm{~mm}, \tau=63.6 \mu \mathrm{s}$, and a striking velocity $\mathrm{V}_{\mathrm{o}}=17.5 \mathrm{~m} / \mathrm{s}$. Both Figs. 5 and 6 show that the onset of unloading is at about $\mathrm{t}^{*}=110$ $\mu$ s. So $\tau \leq t^{*}<2 \tau$, and the loading strain in the pulse shaper is calculated from eq (21a) for $0 \leq t$ $<\tau$ and from eq (30) for $\tau \leq t<t^{*}$. However as with all Hopkinson experimental techniques, we do not measure stresses or strains in the pulse shaper but infer these quantities through a wave analysis and downstream strain measurements on the incident bar. Thus, the model that predicts incident bar stresses shown in Figs. 5 and 6 are calculated from eqs (16), (17a), and (39).

. For $\mathrm{t} \geq \mathrm{t}^{*}$ or $\mathrm{t}$ greater than about $110 \mu \mathrm{s}$, the pulse shaper is unloading. We take the unloading Young's modulus as $\mathrm{E}_{\mathrm{p}}=117 \mathrm{GPa}$ in eq (33) and calculate the unloading pulse shaper strain responses for $t^{*} \leq t<2 \tau(2 \tau=127 \mu \mathrm{s})$ from eq (36) and for $2 \tau \leq t<3 \tau(3 \tau=191 \mu \mathrm{s})$ from eqs (37a) and (37b). The incident bar stresses predicted for unloading in Figs. 5 and 6 can be expressed in terms of the strain in the pulse shaper. We combine eqs (13), (14), and (33) and obtain 


$$
\sigma_{\mathrm{i}}=\frac{\mathrm{a}_{\mathrm{o}}}{\mathrm{A}\left(1-\varepsilon_{\mathrm{p}}\right)} \sigma_{\mathrm{p}}^{*}-\mathrm{E}_{\mathrm{p}}\left(\varepsilon_{\mathrm{p}}^{*}-\varepsilon_{\mathrm{p}}\right)
$$

where $\sigma_{\mathrm{p}}{ }^{*}$ and $\varepsilon_{\mathrm{p}}{ }^{*}$ are the peak pulse shaper stress and strain at the onset of unloading.

A common feature for the hard copper data is a well defined kink found early in the incident stress-time data. The kink shown in Fig. 5 has an incident stress level of about $70 \mathrm{MPa}$ and is caused by the transition from elastic to plastic deformation in the pulse shaper. The incident stress level of this kink can be adjusted by changing the initial pulse shaper diameter. In addition, the data in Fig. 6 shows the kink is removed for an annealed copper pulse shaper that has a very small yield strength.

\section{Modified SHPB Experiments with Macor}

The analytical models presented in the section, Models for Sample Equilibrium and Constant Strain Rate, examine the sample response produced by an incident stress pulse. The incident stress pulse given by eq (7) is taken as a quadratic function, but these models assume the sample has a linear stress-strain response. While most brittle materials, such as rocks ${ }^{12}$ or ceramics, have quasi-linear, dynamic stress-strain responses, slight deviations from linear can change the strain-rate histories over the test duration. Because we do not know the sample, stress-strain response before a test, some experimental trials are required before we achieve dynamic stress equilibrium and nearly constant strain rate. The analytical models show trends that help guide and minimize our experimental trials. 
We begin this process by first conducting a few quasi-static, stress-strain experiments with a new sample material. Then, we linearize this quasi-static data and obtain a value for $E_{s}$ for eq (6). Our early SHPB experiments are conducted with nearly linear incident stress pulses such as those for limestone ${ }^{12}$ or the incident pulse shown in Fig. 6. We check for sample equilibrium and nearly constant strain rate with strain measurements and eqs (1a), 1b), and (3). In this study, we learned that it was relatively easy to obtain sample equilibrium and more difficult to obtain a nearly constant strain rate over most of the test duration. For the Macor results presented in this section, analytical and experimental trials suggest the concave downward incident stress pulse shown in Fig. 7 produced a nearly constant strain rate.

To demonstrate our modified SHPB technique, we present results from two pulse shaped experiments with the machineable glass ceramic, Macor ${ }^{19}$. Data from experiments with Macor show that the samples are in dynamic stress equilibrium and have nearly constant strain rates over most of the duration of the tests. In addition, we carefully bracket sample failure with one test where the sample fails with catastrophic damage and a second test where the sample is recovered intact. Thus, intact samples that experience strains beyond the elastic region and postpeak stresses can be retrieved for microstructural evaluations.

The striker, incident, and transmission bars shown in Fig. 1 were made from high strength, maraging VM 350 steel (Vasco Pacific, Montebello, CA) and have density $p=8100$ $\mathrm{kg} / \mathrm{m}^{3}$, Young's modulus $\mathrm{E}=200 \mathrm{GPa}$, and bar wave velocity $\mathrm{c}=4970 \mathrm{~m} / \mathrm{s}$. The incident and transmission bars had diameters of $19.05 \mathrm{~mm}$ and lengths of 2130 and $915 \mathrm{~mm}$, respectively. Strain gages shown in Fig. 1 were located at $1065 \mathrm{~mm}$ from the impact surface of the incident bar and at $458 \mathrm{~mm}$ from the sample/ bar interface on the transmission bar. The Macor samples had a length and diameter of $9.53 \mathrm{~mm}$. To obtain incident stress pulses that would strain the 
Macor samples at a nearly constant strain rate over most of the test durations, $10.21-\mathrm{mm}$ diameter, 0.79-mm-thick, annealed C11000 copper pulse shapers were used. All of the above mentioned parameters remained fixed for the two experiments presented in this section. However, the first experiment used a 19.05 -mm-diameter, 127 -mm-long, striker bar, and the second experiment used a 19.05-mm-diameter, 101.6-mm-long, striker bar. The effective densities and wave velocities that correct for the added mass of the sabots were $\rho_{\mathrm{st}}=8790 \mathrm{~kg} / \mathrm{m}^{3}$, $\mathrm{c}_{\mathrm{st}}=4770 \mathrm{~m} / \mathrm{s}$ and $\rho_{\mathrm{st}}=8760 \mathrm{~kg} / \mathrm{m}^{3}, \mathrm{c}_{\mathrm{st}}=4780 \mathrm{~m} / \mathrm{s}$ for the $125-\mathrm{mm}$-long and $101.6-\mathrm{mm}$-long striker bars, respectively. Both striker bars were launched to a striking velocity of $12.2 \mathrm{~m} / \mathrm{s}$.

Figures 7,8 , and 9 show data for the experiment conducted with the 127 -mm-long striker bar. In Fig. 7, we show the measured incident stress pulse and a prediction from our pulse shaping model. Figure 8 shows stresses and stations 1 and 2 shown in Fig. 1. The stress at the incident bar/ sample interface $\sigma_{1}$ is calculated from eq (1a) and strains measured on the incident bar, and stress at the transmission bar/ sample interface $\sigma_{2}$ is calculated from eq (1b) and the measured transmitted strain. These interface stresses are in reasonably good agreement, which implies that the sample is nearly in dynamic stress equilibrium. Strain rate in the sample, shown in Fig. 9, is calculated from eq (3) and the measured reflected strain in the incident bar. The average strain rate is about $300 \mathrm{~s}^{-1}$ over $20 \mu \mathrm{s}$ to $60 \mu \mathrm{s}$. At about $60 \mu$ s the sample begins to fail and eventually fails with catastrophic damage.

Figures 10,11 , and 12 show data for the experiment conducted with the 101.6-mm-long striker bar. Figure 12 shows an average strain rate of $280 \mathrm{~s}^{-1}$ over $20 \mu \mathrm{s}$ to $50 \mu \mathrm{s}$. At $50 \mu \mathrm{s}$, the sample unloads and was recovered intact.

Figure 13 shows dynamic and quasi-static stress-strain data for the Macor samples. The sample with an average strain rate of $\dot{\varepsilon}_{\mathrm{s}}=280 \mathrm{~s}^{-1}$ experienced strain beyond the elastic region 
and post-peak stress. Samples such as these can be retrieved for post-test, microstructural evaluations.

\section{Summary}

We present analytical models and experimental techniques that provide procedures to obtain dynamic, compressive stress-strain data for brittle materials. The conventional split Hopkinson pressure bar apparatus is modified by shaping the incident pulse such that the samples are in dynamic stress equilibrium and have nearly constant strain rate over most of the test duration. A thin disk of annealed or hard C11000 copper is placed on the impact surface of the incident bar in order to shape the incident pulse. After impact by the striker bar, the copper disk deforms plastically and spreads the pulse in the incident bar. We present an analytical model and data that show a wide variety of incident strain pulses can be produced by varying the geometry of the copper disks and the length and striking velocity of the striker bar. Model predictions are in good agreement with measurements. In addition, we present data for a machineable glass ceramic material, Macor, that shows pulse shaping is required to obtain dynamic stress equilibrium and nearly constant strain rate over most of the test duration.

\section{Acknowledgments}

This work was sponsored by the U.S. Army Engineer Research and Development Center (ERDC) at the Waterways Experiment Station under a laboratory director's discretionary research program, the U.S. Army Corps of Engineers Hardened Structures Research Programs, and by the Sandia National Laboratories Joint DoD/ DOE Penetration Technology Program. Sandia is a multi-program laboratory operated by Sandia Corporation, a Lockheed Martin Company, for the United States Department of Energy under Contract DE-AC04-94AL8500. The authors gratefully acknowledge permission from the Director, Geotechnical and Structures Laboratory, ERDC to publish this work. 


\section{References}

1. Kolsky, H., "An Investigation of the Mechanical Properties of Materials at Very High Rates of Loading," Proc. Royal Soc. Lon., B, 62, 676-700, (1949).

2. Kolsky, H., Stress Waves in Solids. Dover, New York (1963).

3. Nicholas, T., "Material Behavior at High Strain Rates," Impact Dynamics, Chapter 8, John Wiley \& Sons, New York, (1982).

4. Nemat-Nasser, S., Isaacs, J. B. and Starrett, J. E., "Hopkinson Techniques for Dynamic Recovery Experiments," Proc. R. Soc. Lond., A, 435, 371-391,(1991).

5. Ramesh, K. T. and Narasimhan, S., "Finite Deformations and the Dynamic Measurement of Radial Strains in Compression Kolsky Bar Experiments," Int. J. Solids Structures 33, 3723-3738, (1996).

6. Gray, G. T., "Classic Split-Hopkinson Pressure Bar Technique," LA-UR-99-2347, Los Alamos National Laboratory, Los Alamos, NM 87545. (1999). To be published in ASM Volume 8, Chapter 6A-Mechanical Testing, ASM International, Materials Park, OH, 44073.

7. Gray, G. T. and Blumenthal, W. R., "Split-Hopkinson Pressure Bar Testing of Soft Materials, "LA-UR-99-4878, Los Alamos National Laboratory, Los Alamos, NM87545. (1999). To be published in ASM Volume 8, Chapter 6E-Mechanical Testing, ASM International, Materials Park, OH, 44073.

8. Yadav, S., Chichili, D. R., and Ramesh, K. T., "The Mechanical Response of a 606I-T6 Al/Al2O3 Metal Matrix Composite at High Rates of Deformation," Acta metall. Mater. 43, 4453-4464, (1995).

9. Rogers, W. P. and Nemat-Nasser, S., "Transformation Plasticity at High Strain Rate in Magnesia-Partially-Stabilized Zirconia," J. Am. Ceram. Soc. 73, 136-139, (1990).

10. Chen, W. and Ravichandran, G., "Dynamic Compressive Failure of a Glass Ceramic Under Lateral Confinement," J. Mech. Phys. Solids. 45, 1303-1328, (1997). 
11. Ravichandran, G. and Subhash, G., "Critical Appraisal of Limiting Strain Rates for Compression Testing of Ceramics in a Split Hopkinson Pressure Bar, " J. Am. Ceram. Soc. 77, 263-267, (1994).

12. Frew, D. J., Forrestal, M. J., and Chen, W., "A Split Hopkinson Bar Technique to Determine Compressive Stress-Strain Data for Rock Materials, " EXPERIMENTAL MECHANICS, in press.

13. Duffy, J., Campbell, J. D., and Hawley, R. H., "On the use of a torsional split Hopkinson bar to study rate effects in 1100-0 aluminum," ASME J. Appl. Mech. 37, 83-91, (1971).

14. Wu, X. J. and Gorham, D. A., "Stress Equilibrium in the Split Hopkinson Pressure Bar Test,"J. PHYS. IV FRANCE 7, C3, 91-96, (1997).

15. Togami, T. C., Baker, W. E. and Forrestal, M. J., "A Split Hopkinson Bar Technique to Evaluate the Performance of Accelerometers," J. Appl. Mech. 63, 353-356, (1996).

16. Chen, W., Zhang, B., and Forrestal, M. J., "A Split Hopkinson Bar technique for lowimpedance materials," EXPERIMENTAL MECHANICS 39, 81-85, (1999).

17. Christensen, R. J., Swanson, S. R., and Brown, W. S., "Split-Hopkinson-bar Tests on Rock under Confining Pressure," EXPERIMENTAL MECHANICS 29, 508-513, (1972).

18. Lewis, C. F., "Properties and Selection: Nonferrrous Alloys and Pure Metals," In Metals Handbook, $9^{\text {th }}$ Edition, 2, American Society for Metals, Metals Park, OH, (1979).

19. Corning Incorporated, "Macor Machineable Glass Ceramic: Safety and Health Issues," Technical Bulletin, Macor-03, Corning, New York (1992).

20. Frew, D. J., "The dynamic response of brittle materials from penetration and split Hopkinson pressure bar experiments, " Ph. D. thesis, Arizona State University (2000).

21. Davies, E. D. H. and Hunter S. C. "The dynamic compression testing of solids by the method of the split Hopkinson pressure bar," J. Mech. Phys. Solids 11, 155-179, (1963). 
22. Baron, H. G. "Stress/strain curves for some metals and alloys at low temperatures and high rates of strain," J. Iron St. Inst. 182, 354-365, (1956). 


\section{Figure Titles}

Fig. 1- Schematic of a conventional split Hopkinson pressure bar (SHPB) or Kolsky bar

Fig. 2- Schematic of the loading end of a SHPB with a pulse shaper

Fig. 3- Data and response function for hard (HRB 45) C11000 copper

Fig. 4- Data and response functions for annealed C11000 copper

Fig. 5- Incident bar stress data and model prediction for a hard (HRB 45) C11000 copper pulse shaper

Fig. 6- Incident bar stress data and model prediction for an annealed C11000 copper pulse shaper

Fig. 7- Incident bar stress data and model prediction for an annealed C11000 copper pulse shaper

Fig. 8- Interface stresses from a pulse shaped SHPB experiment with a Macor sample

Fig. 9- Strain rate from a pulse shaped SHPB experiment with a Macor sample

Fig. 10- Incident bar stress data and model prediction for an annealed C11000 copper pulse shaper

Fig. 11-Interface stresses from a pulse shaped SHPB experiment with a Macor sample

Fig. 12-Strain rate from a pulse shaped SHPB experiment with a Macor sample

Fig. 13-Quasi-static and dynamic stress-strain data for Macor 


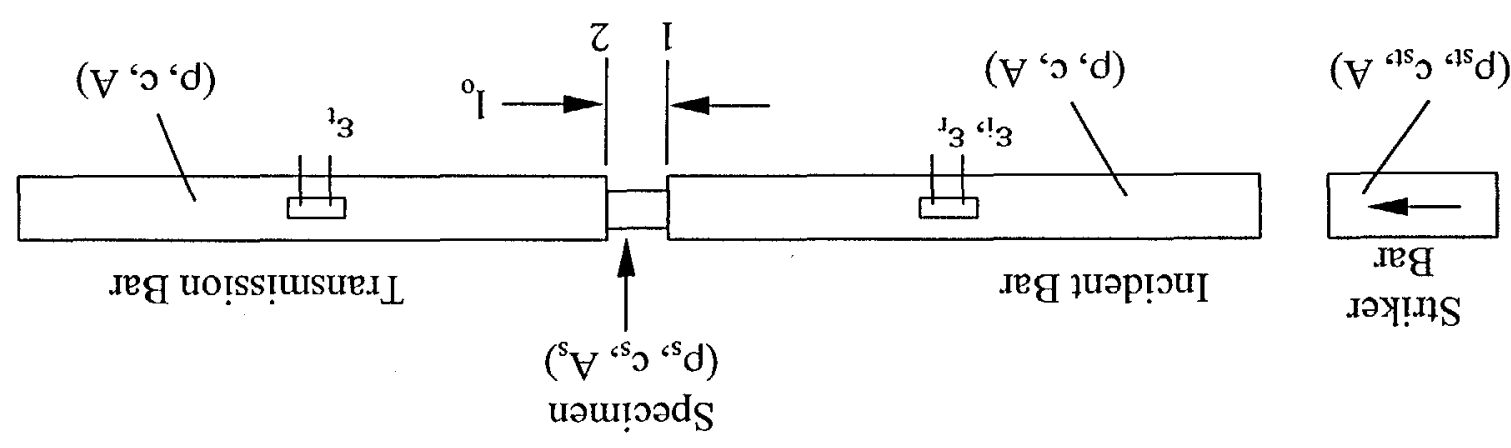


(q)

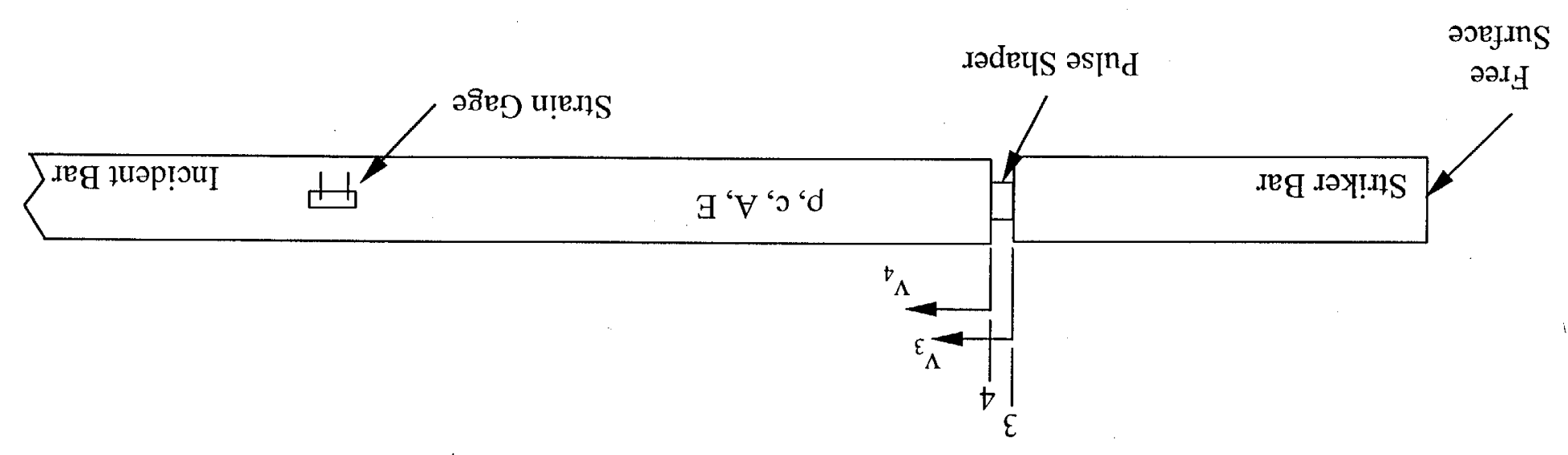

(e)

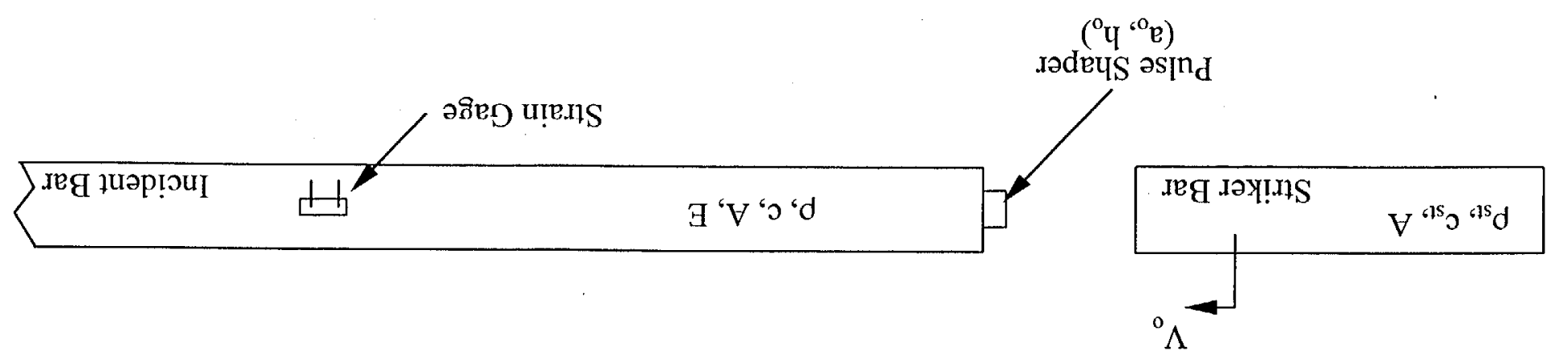


$\frac{\pi}{6}$

True Axial Stress (MPa)

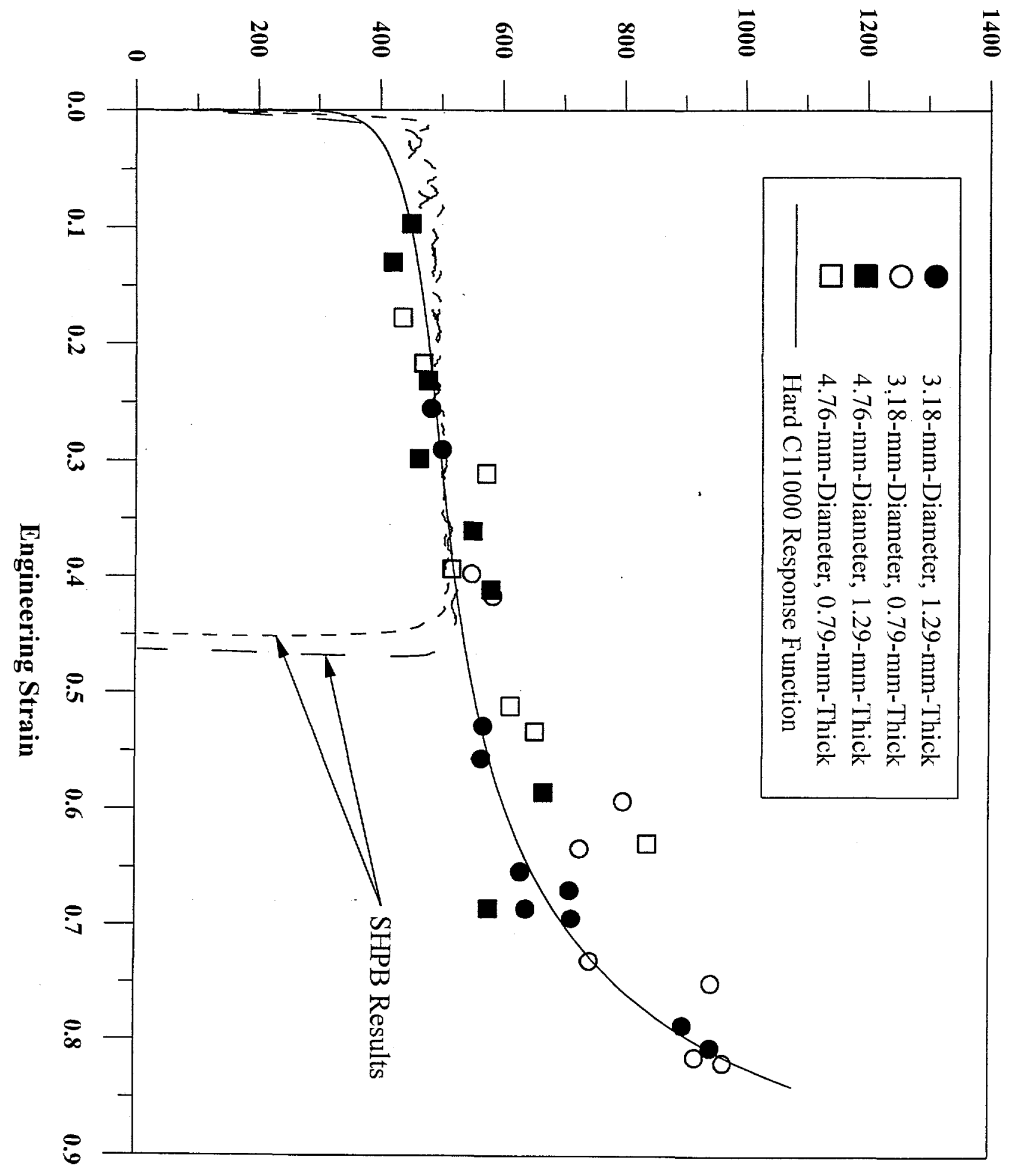


$\frac{\pi}{6}$

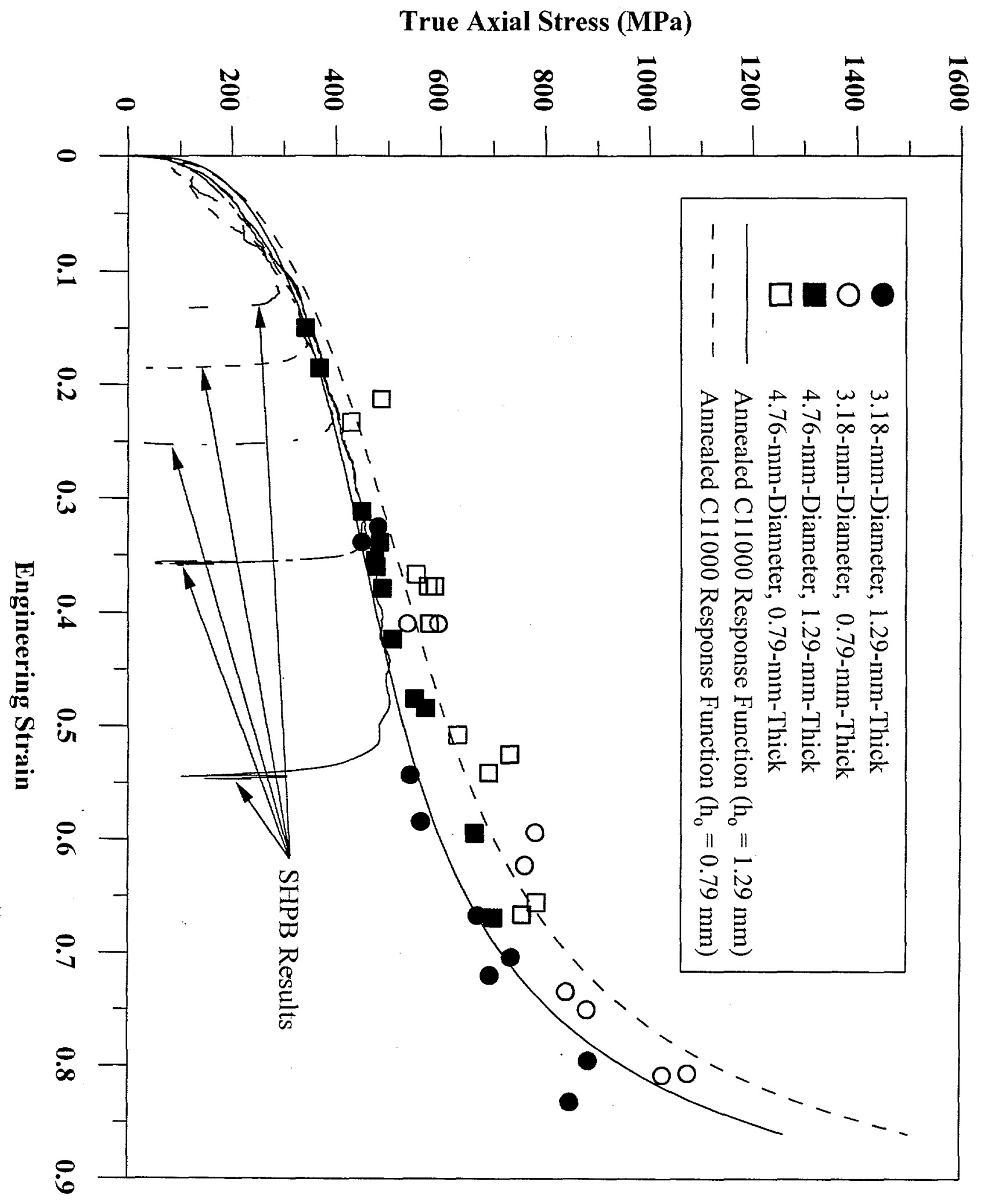


$\frac{\pi}{6}$

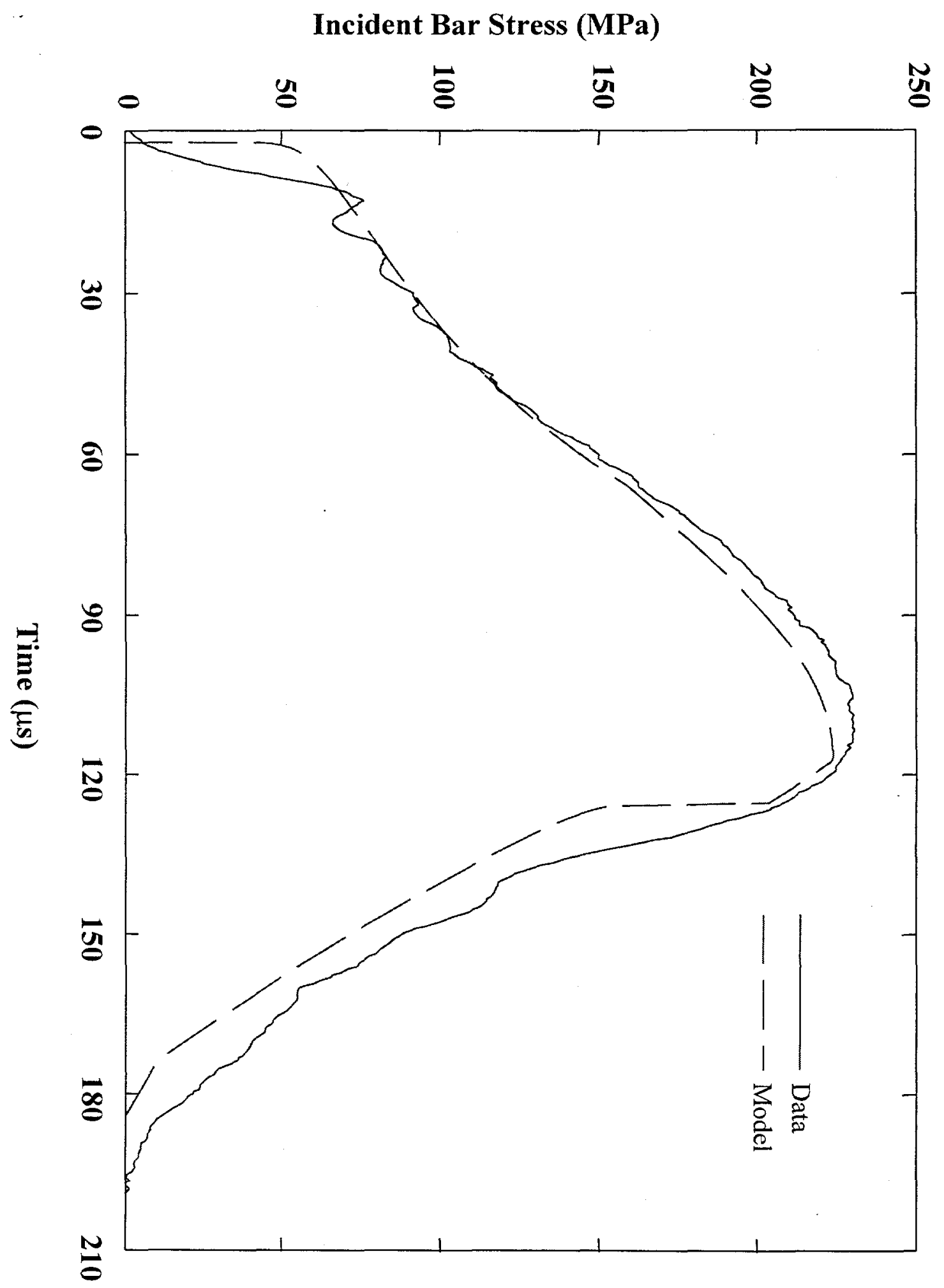


$\frac{7}{6}$

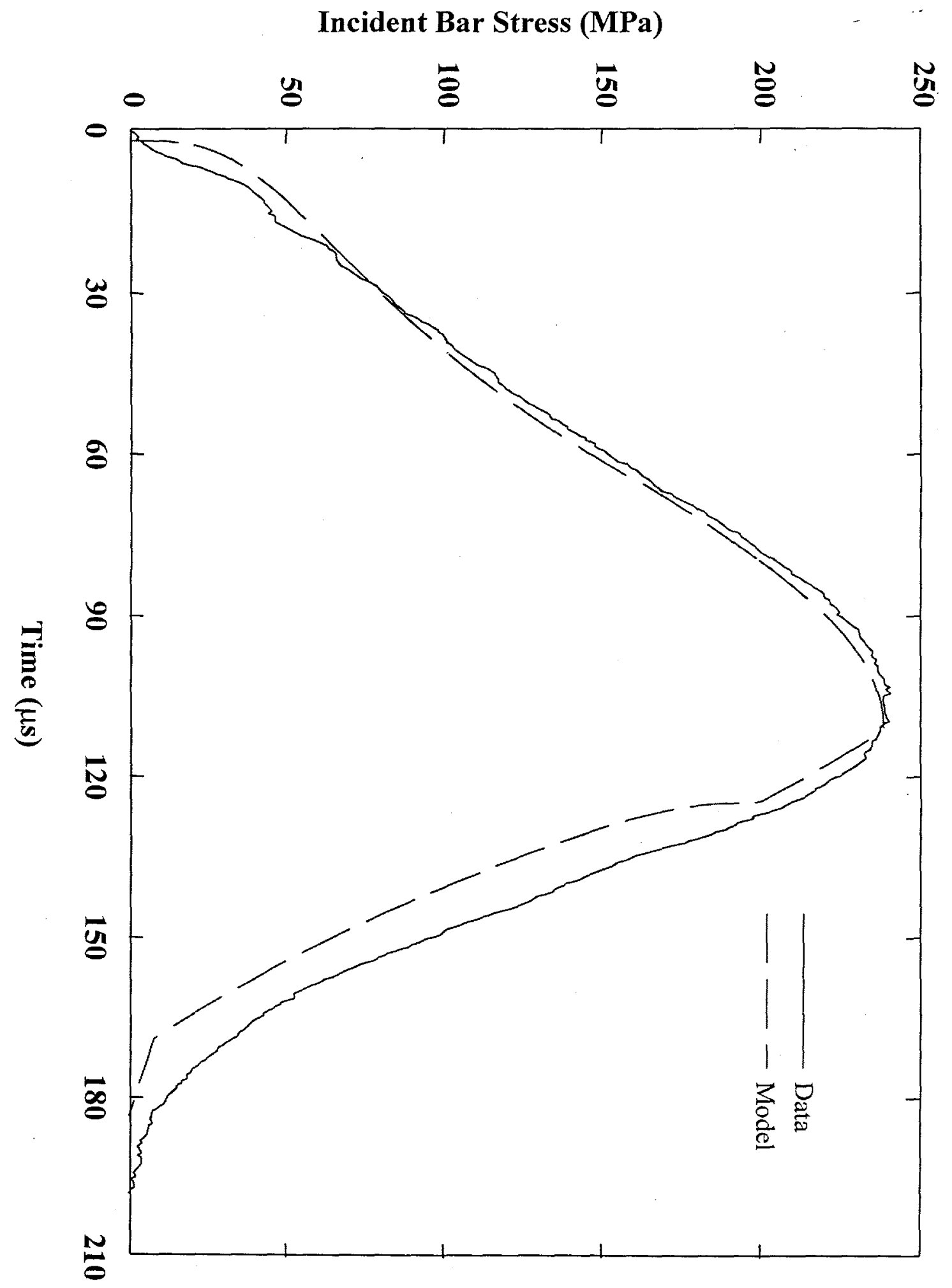


$\frac{\pi}{6}$

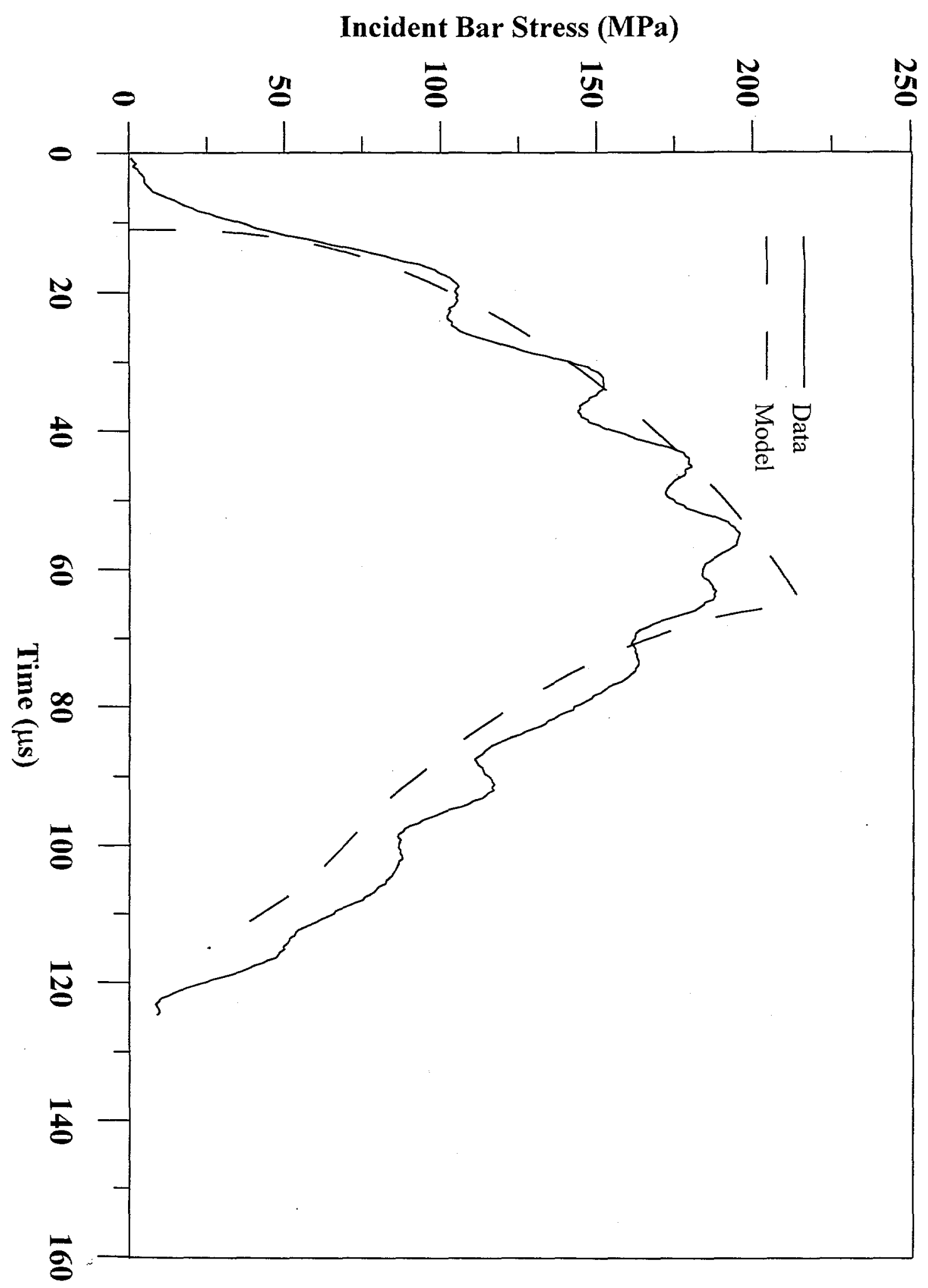


$\frac{\pi}{\infty}$

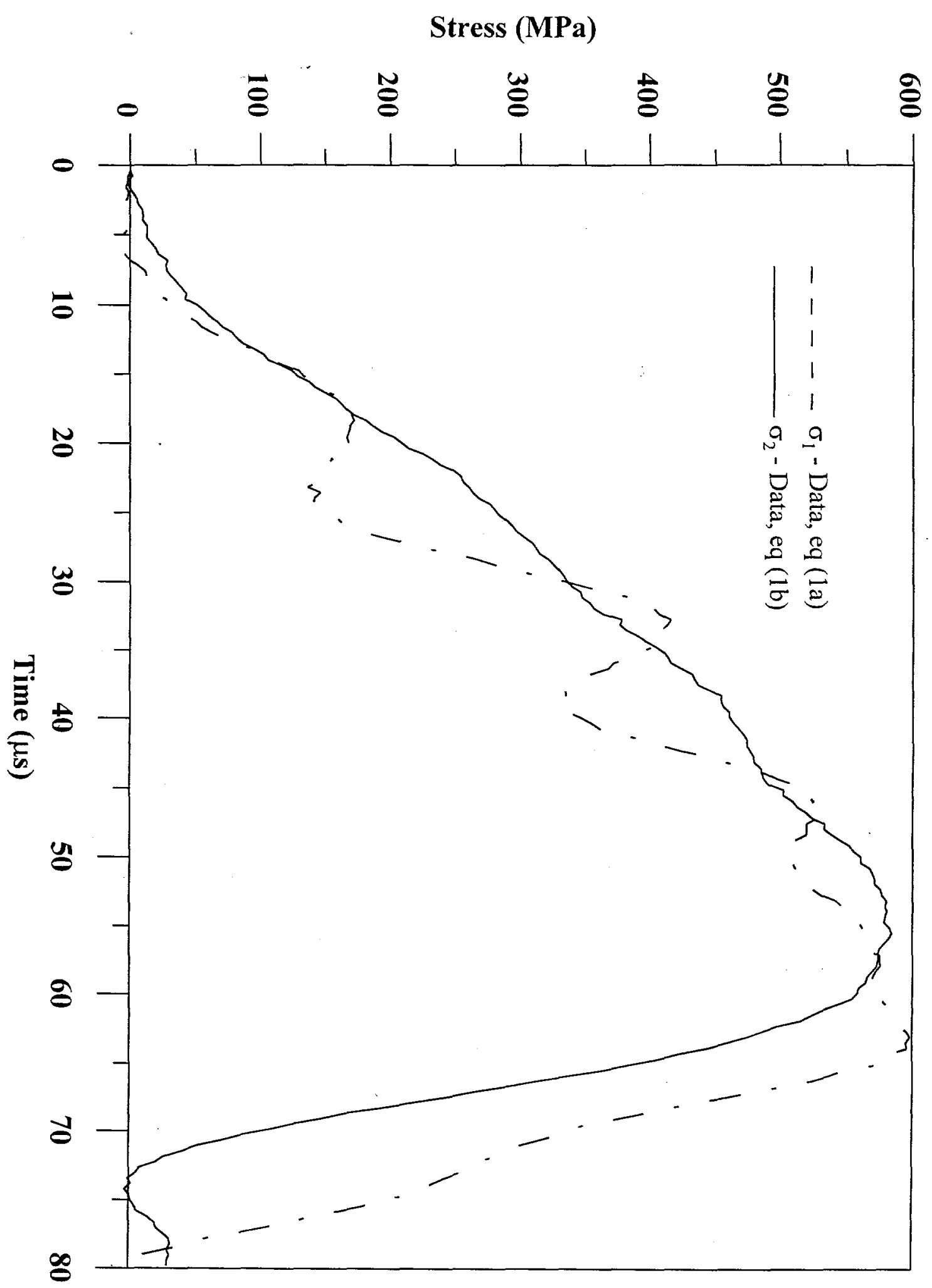


$\frac{7}{6}$

Strain Rate $\left(\mathrm{s}^{-1}\right)$

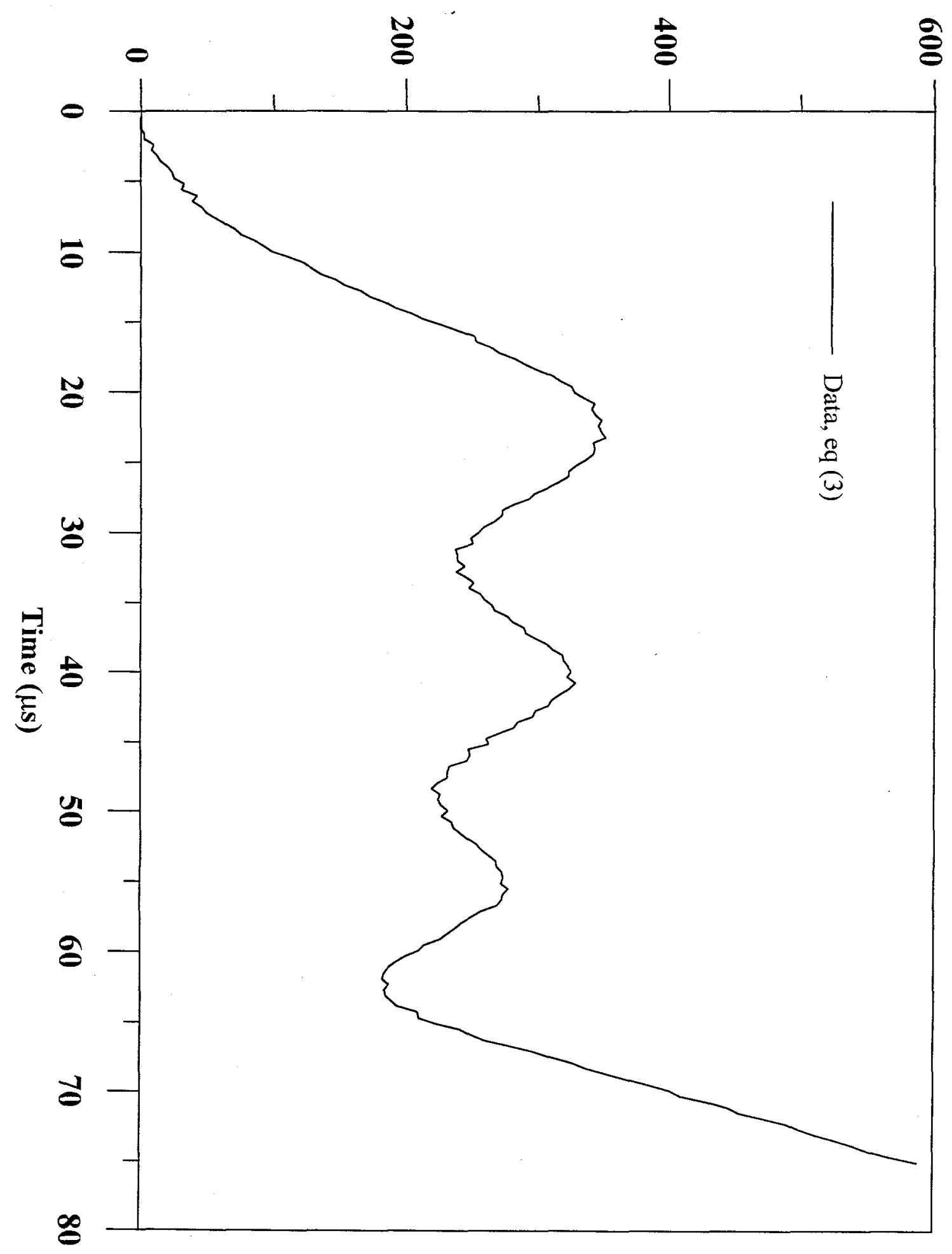


$\frac{\pi}{0}$
0

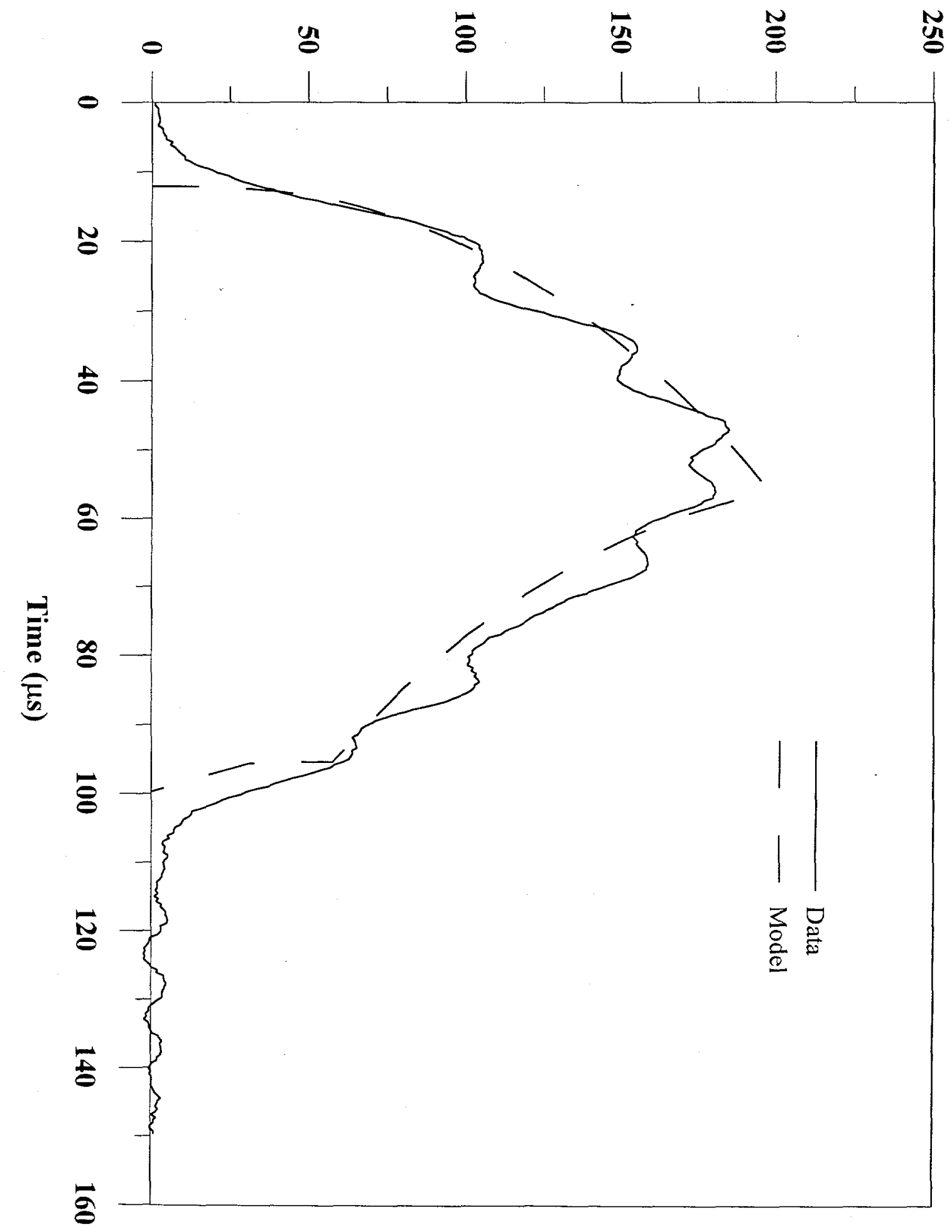


$\stackrel{\frac{\pi}{6}}{=}$

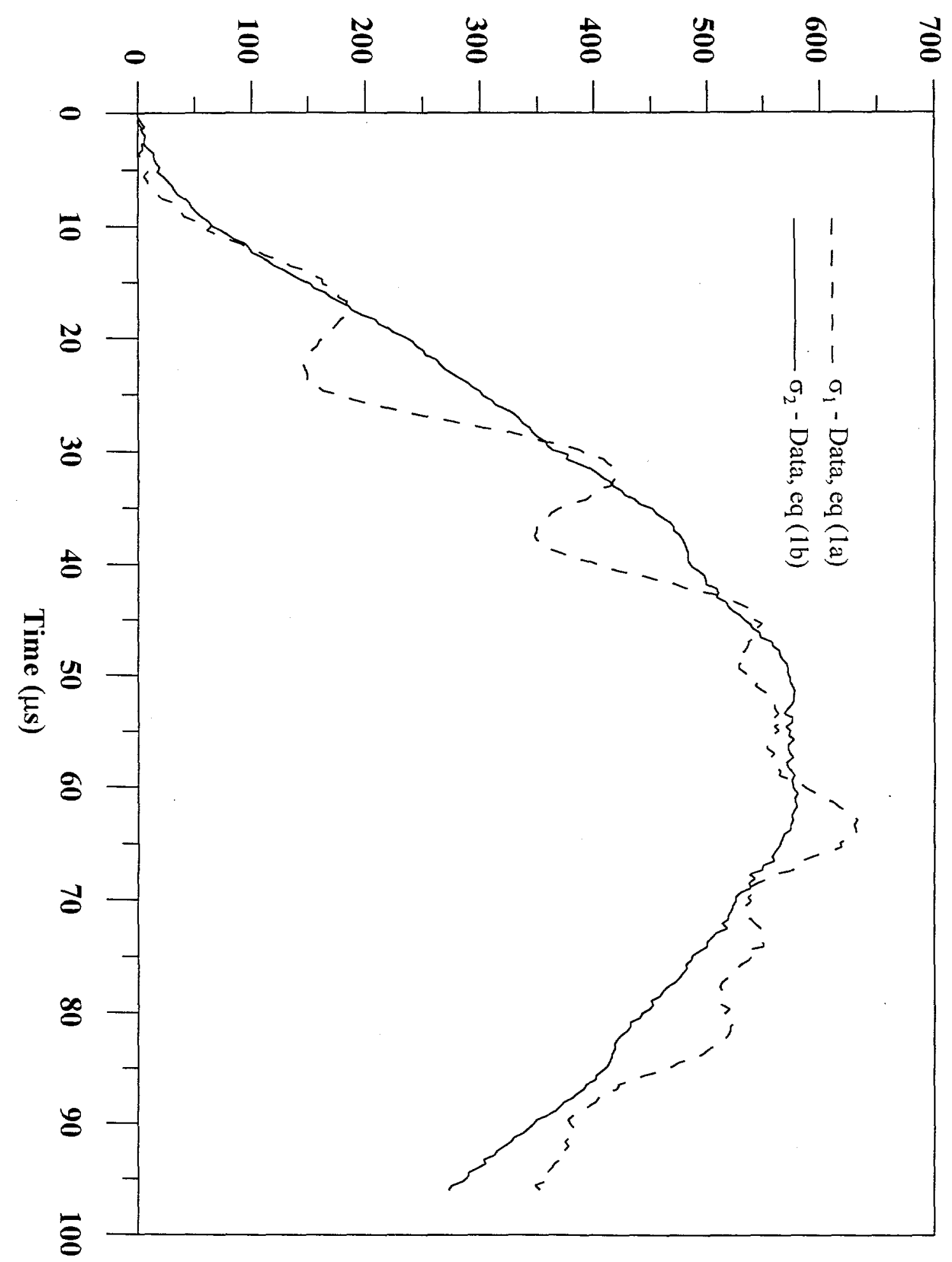


$\frac{\pi}{n}$

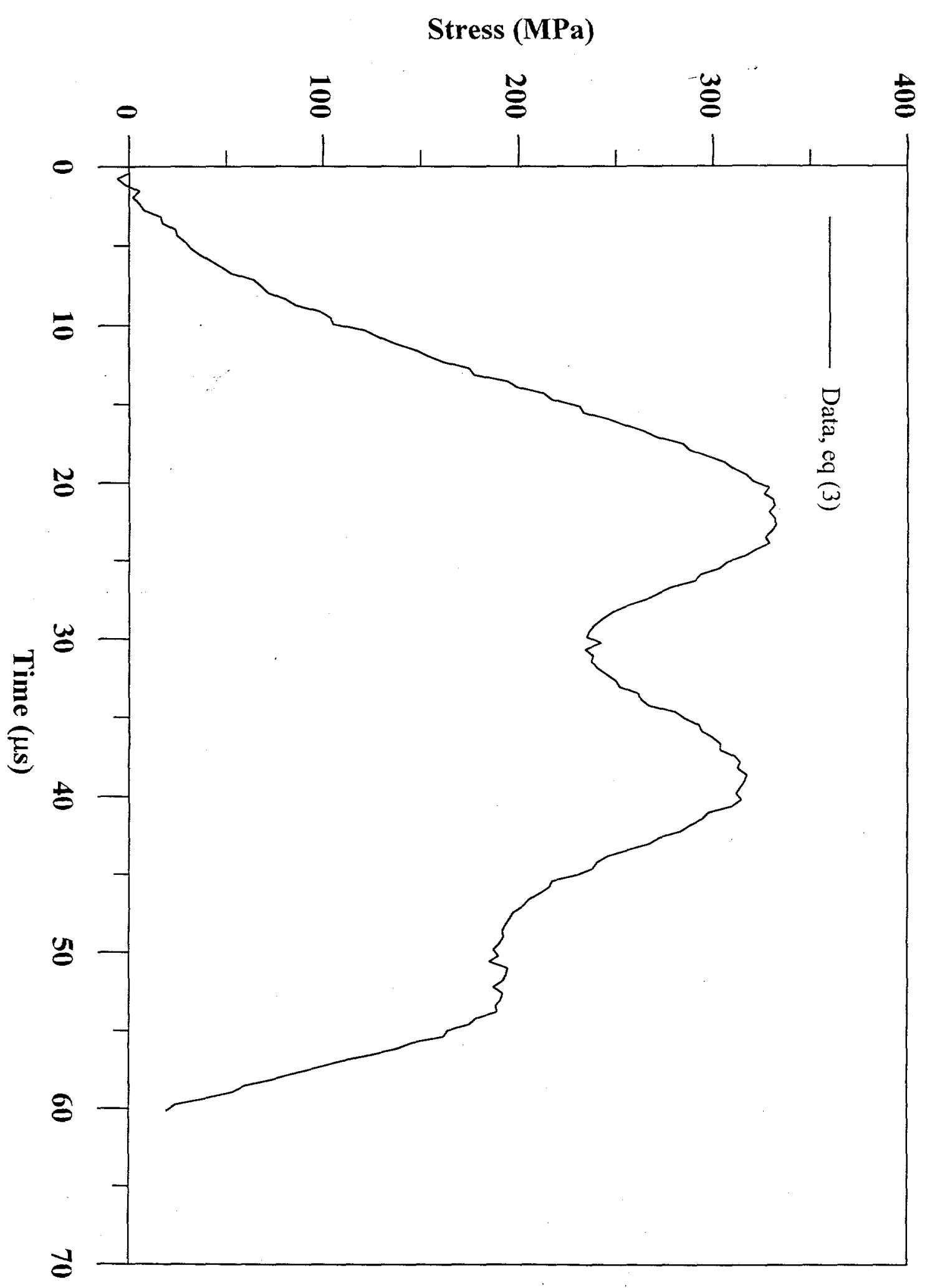


$\frac{\pi}{\omega}$

Stress (MPa)

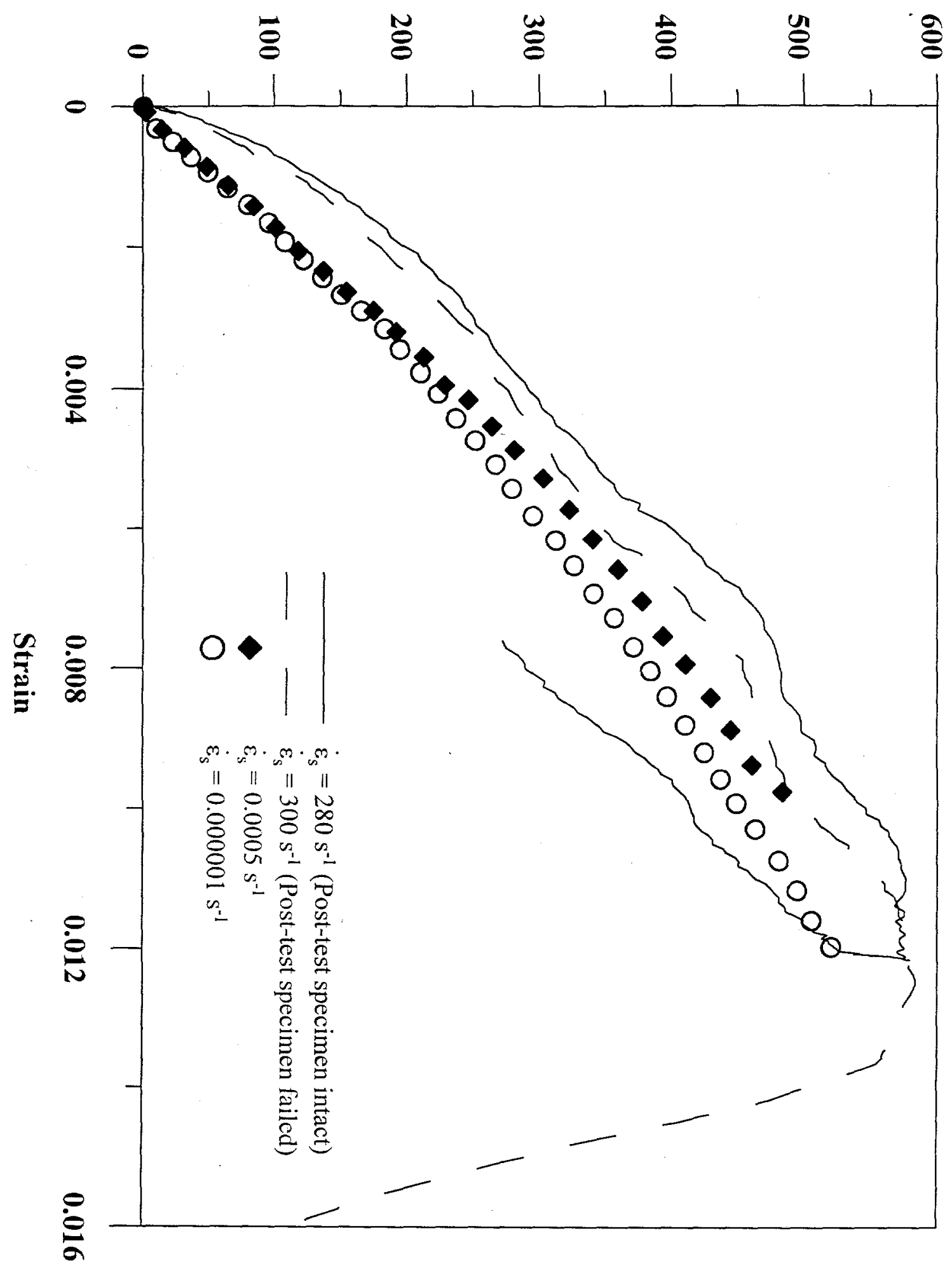

